NASA/TM-2015-218848

\title{
Measurements and Predictions of the Noise From Three-Stream Jets
}

Brenda S. Henderson

Glenn Research Center, Cleveland, Ohio

Stewart J. Leib

Ohio Aerospace Institute, Brook Park, Ohio

Mark P. Wernet

Glenn Research Center, Cleveland, Ohio 


\section{NASA STI Program . . . in Profile}

Since its founding, NASA has been dedicated to the advancement of aeronautics and space science. The NASA Scientific and Technical Information (STI) Program plays a key part in helping NASA maintain this important role.

The NASA STI Program operates under the auspices of the Agency Chief Information Officer. It collects, organizes, provides for archiving, and disseminates NASA's STI. The NASA STI Program provides access to the NASA Technical Report Server-Registered (NTRS Reg) and NASA Technical Report ServerPublic (NTRS) thus providing one of the largest collections of aeronautical and space science STI in the world. Results are published in both non-NASA channels and by NASA in the NASA STI Report Series, which includes the following report types:

- TECHNICAL PUBLICATION. Reports of completed research or a major significant phase of research that present the results of NASA programs and include extensive data or theoretical analysis. Includes compilations of significant scientific and technical data and information deemed to be of continuing reference value. NASA counter-part of peer-reviewed formal professional papers, but has less stringent limitations on manuscript length and extent of graphic presentations.

- TECHNICAL MEMORANDUM. Scientific and technical findings that are preliminary or of specialized interest, e.g., "quick-release" reports, working papers, and bibliographies that contain minimal annotation. Does not contain extensive analysis.
- CONTRACTOR REPORT. Scientific and technical findings by NASA-sponsored contractors and grantees.

- CONFERENCE PUBLICATION. Collected papers from scientific and technical conferences, symposia, seminars, or other meetings sponsored or co-sponsored by NASA.

- SPECIAL PUBLICATION. Scientific, technical, or historical information from NASA programs, projects, and missions, often concerned with subjects having substantial public interest.

- TECHNICAL TRANSLATION. Englishlanguage translations of foreign scientific and technical material pertinent to NASA's mission.

For more information about the NASA STI program, see the following:

- Access the NASA STI program home page at http://www.sti.nasa.gov

- E-mail your question to help@sti.nasa.gov

- Fax your question to the NASA STI Information Desk at 757-864-6500

- Telephone the NASA STI Information Desk at 757-864-9658

- Write to:

NASA STI Program

Mail Stop 148

NASA Langley Research Center Hampton, VA 23681-2199 
NASA/TM-2015-218848

\section{Measurements and Predictions of the Noise From Three-Stream Jets}

Brenda S. Henderson

Glenn Research Center, Cleveland, Ohio

Stewart J. Leib

Ohio Aerospace Institute, Brook Park, Ohio

Mark P. Wernet

Glenn Research Center, Cleveland, Ohio

Prepared for the

Aviation 2015

sponsored by American Institute of Aeronautics and Astronautics

Dallas, Texas, June 22-26, 2015

National Aeronautics and

Space Administration

Glenn Research Center

Cleveland, Ohio 44135 
Trade names and trademarks are used in this report for identification only. Their usage does not constitute an official endorsement, either expressed or implied, by the National Aeronautics and Space Administration.

This work was sponsored by the Fundamental Aeronautics Program at the NASA Glenn Research Center.

Level of Review: This material has been technically reviewed by technical management.

Available from

NASA STI Program

Mail Stop 148

NASA Langley Research Center

Hampton, VA 23681-2199
National Technical Information Service 5285 Port Royal Road Springfield, VA 22161 703-605-6000

This report is available in electronic form at http://www.sti.nasa.gov/ and http://ntrs.nasa.gov/ 


\title{
Measurements and Predictions of the Noise From Three-Stream Jets
}

\author{
Brenda S. Henderson \\ National Aeronautics and Space Administration \\ Glenn Research Center \\ Cleveland, Ohio 44135 \\ Stewart J. Leib \\ Ohio Aerospace Institute \\ Brook Park, Ohio 44142 \\ Mark P. Wernet \\ National Aeronautics and Space Administration \\ Glenn Research Center \\ Cleveland, Ohio 44135
}

\begin{abstract}
An experimental and numerical investigation of the noise produced by high-subsonic and supersonic three-stream jets was conducted. The exhaust system consisted of externally-mixed-convergent nozzles and an external plug. Bypass- and tertiary-to-core area ratios between 1.0 and 2.5, and 0.4 and 1.0, respectively, were studied. Axisymmetric and offset tertiary nozzles were investigated for heated and unheated conditions. For axisymmetric configurations, the addition of the third stream was found to reduce peak- and high-frequency acoustic levels in the peak-jet-noise direction, with greater reductions at the lower bypass-to-core area ratios. For the offset configurations, an offset duct was found to decrease acoustic levels on the thick side of the tertiary nozzle relative to those produced by the simulated twostream jet with up to $8 \mathrm{~dB}$ mid-frequency noise reduction at large angles to the jet inlet axis. Noise reduction in the peak-jet-noise direction was greater for supersonic core speeds than for subsonic core speeds. The addition of a tertiary nozzle insert used to divert the third-stream jet to one side of the nozzle system provided no noise reduction. Noise predictions are presented for selected cases using a method based on an acoustic analogy with mean flow interaction effects accounted for using a Green's function, computed in terms of its coupled azimuthal modes for the offset cases, and a source model previously used for round and rectangular jets. Comparisons of the prediction results with data show that the noise model predicts the observed increase in low-frequency noise with the introduction of a third, axisymmetric stream, but not the high-frequency reduction. For an offset third stream, the model predicts the observed trend of decreased sound levels on the thick side of the jet compared with the thin side, but the predicted azimuthal variations are much less than those seen in the data. Also, the shift of the spectral peak to lower frequencies with increasing polar angle is over-predicted. For an offset third stream with a heated core, it is shown that including the enthalpy-flux source terms in the acoustic analogy model improves predictions compared with those obtained using only the momentum flux.
\end{abstract}

\section{Introduction}

Exhaust-system noise emission continues to be an issue for commercial and military aircraft and is, therefore, the subject of ongoing research efforts as to its understanding, prediction and reduction.

National and international regulations are imposing significant limitations on the noise footprint of aircraft operations, which are driving the development of noise-reduction concepts. Assessment of proposed noise-reduction concepts involves the combined use of experimental testing and theoretical and numerical analysis. Detailed experimental measurements are necessary to screen potential noise-reduction 
concepts and to provide a database for the construction and validation of reduced-order models which can then be used in parametric studies to optimize the most promising designs. These reduced-order models can be purely (or semi) empirical (Ref. 1), or statistically based methods, such as those based on an acoustic analogy as in Khavaran, Bridges, and Georgiadis (Ref. 2) and Goldstein and Leib (Ref. 3).

Future engine architectures may provide a third exhaust stream that will be available for potential noise reduction technologies. A third jet stream allows for additional geometric and parametric variation of the nozzle operation, and for an offset of the third stream relative to the core and bypass streams. The introduction of asymmetry into the flow field of the jet provides the potential for redirecting noise away from certain observer locations.

Papamoschou and Debiasi (Ref. 4) studied the effects of offsetting the fan stream of dual-stream supersonic jets. Their results showed a decrease in Mach wave radiation on the thicker side of the jet (created by the offset) and they attributed this reduction to increased mixing and a reduction of the potential core length with the offset fan stream. Flow and noise measurements in eccentric dual-stream jets by Zaman (Ref. 5) seemed to confirm these results.

A significant amount of subsequent experimental work was carried out by Papamoschou and coworkers and researchers at NASA (Refs. 6,7, 8, 9, 10,11) testing and refining various offset concepts for dual-stream jets. Concepts investigated included the use of s-ducts, guide vanes and fan-stream wedges to create the desired offset. Computational studies (Refs. 12 and 13) were also carried out, based on the Reynolds-averaged Navier Stokes equations, to guide the design and selection of parameters used in these experiments and to help understand the impact of the different offset concepts on the flow. A model, based on Lighthill's acoustic analogy formulation (Ref. 14), for the noise radiated by asymmetric, dual-stream jets was presented by Papamoschou and Rostamimonjezi (Ref. 15).

Some of the concepts proposed and initially studied in the above works were systematically assessed in the Offset Stream Technology tests at NASA Glenn Research Center (Ref. 16). This test also extended some of these concepts, many of which were initially proposed for supersonic jets, to subsonic flows. The investigation focused on moderate (5) and high (8) bypass ratio exhausts.

Initial experiments by Henderson (Ref. 17) have shown the potential for noise reduction using a third stream under certain flow conditions. Papamoushco, Johnson and Phong (Ref. 18) have carried out experimental work to study the noise-reduction potential of coaxial and offset three-stream jets.

In this paper, results from an experimental and numerical investigation of the noise produced by high-subsonic and supersonic three-stream jets are reported. The exhaust system consisted of externallymixed-convergent nozzles and an external plug. Various bypass- and tertiary-to-core area ratios were studied, with axisymmetric and offset tertiary streams, for heated and unheated conditions.

In Section II the experimental approach is described. Results from the experiments are given in Section III. The acoustic analogy-based noise prediction method is briefly described in Section IV and results using this method are compared with experimental data for select cases in Section V. Conclusions and a discussion of the results are given in Section VI.

\section{Experimental Approach}

The experiments were performed in the Aero-Acoustic Propulsion Laboratory (AAPL) at NASA Glenn shown in Figure 1. The AAPL is a 20 m radius geodesic dome treated with acoustic wedges. The AAPL contains the Nozzle Acoustic Test Rig (NATR), which produces a $1.35 \mathrm{~m}$ diameter simulated forward flight stream reaching Mach numbers of 0.35 and contains the High Flow Jet Exit Rig (HFJER), a three-stream jet engine simulator capable of replicating most commercial turbo-fan engine temperatures and pressures (Ref. 19).

Acoustic measurements were made with the far-field array shown in Figure 1. The array contains 24 microphones located on a $13.7 \mathrm{~m}$ constant radius arc covering polar angles between $45^{\circ}$ and $160^{\circ}$, where angles greater than $90^{\circ}$ are in the downstream direction relative to the nozzle exit. All data were corrected for atmospheric absorption (Ref. 20) and wind tunnel shear layer effects (Ref. 21). Data were acquired using 1/4 in. Bruel and Kjaer microphones without grid caps, pointed directly at the nozzle exit. 


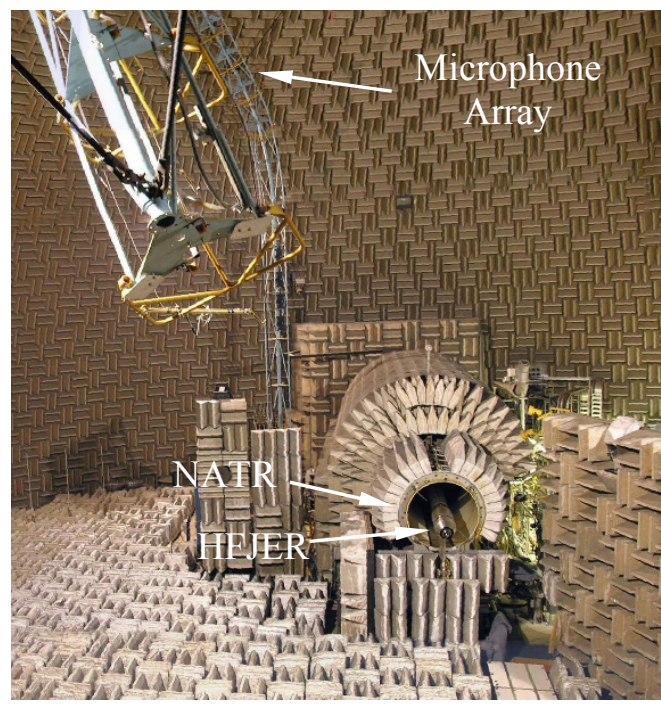

Figure 1.-A photograph of the Aero-Acoustic Propulsion Laboratory (AAPL) showing the Nozzle Acoustic Test Rig (NATR) and the High Flow Jet Exit Rig (HFJER).

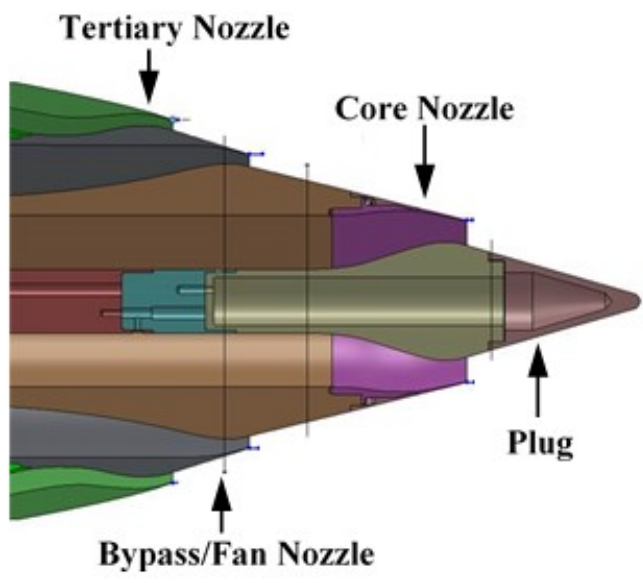

Figure 2.-The axisymmetric-nozzle system used in the three-stream experiments.

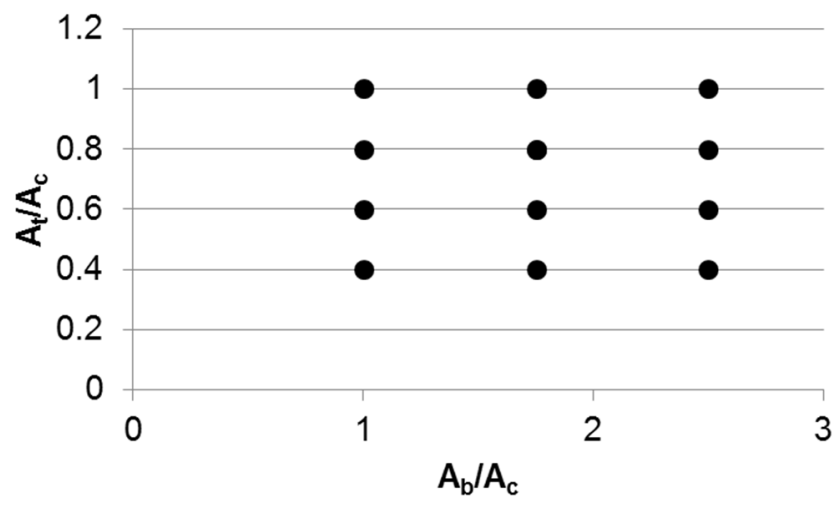

Figure 3.-The nozzle design space used in the experiments.

Microphone sensitivity and frequency response have been applied to all measurements. Narrowband results are presented as power spectral density on a one-foot lossless arc. One-third-octave spectra are also presented on a 1-foot lossless arc.

The axisymmetric experiments used the externally-mixed, externally-plugged, convergent-nozzle system shown in Figure 2 with the range of tertiary-to-core-area ratios $\left(A_{t} / A_{c}\right)$ and bypass-to-core-area ratios $\left(A_{b} / A_{c}\right)$ shown in Figure 3. All nozzle-system configurations used a core-nozzle exit diameter and area of $13.2 \mathrm{~cm}$ and $69.7 \mathrm{~cm}^{2}$, respectively, and a common bypass nozzle. The bypass-to-core-area ratio was varied by using core nozzles with slightly different external contours which resulted in differences in the inner diameter of the bypass nozzle at the bypass-nozzle trailing edge. The tertiary area ratio was varied through a set of tertiary nozzles with the range of exit areas shown in Figure 3.

Two different approaches were used to create asymmetry in the third-stream flow: (1) the introduction of an offset duct upstream of the tertiary nozzle and (2) a tertiary nozzle insert that blocked a circumferential region of the third-stream nozzle exit (Fig. 4). The offset duct, which was combined with the $A_{t} / A_{c}=1.0$ tertiary nozzle, produced a 0.156 in. offset of the tertiary nozzle centerline relative to the centerlines of the core and bypass nozzles. The tertiary-nozzle insert blocked $228^{\circ}$ of the third-stream nozzle exit resulting in $A_{t} / A_{c}=0.6$. 


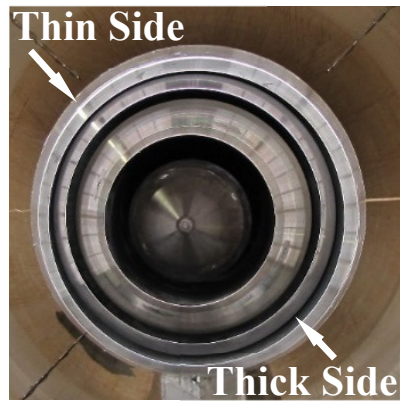

(a)

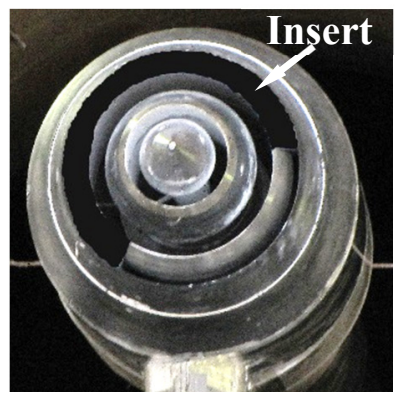

(b)

Figure 4.-Photographs of the offset nozzle systems using (a) the offset duct and (b) the third-stream nozzle inserts.

TABLE 1.-EXPERIMENTAL JET CONDITIONS
\begin{tabular}{|c|c|c|c|}
\hline $\mathbf{N P R}_{\mathbf{c}}$ & $\mathbf{N P R}_{\mathbf{b}}$ & $\mathbf{N P R}_{\mathbf{t}}$ & $\mathbf{N T R}_{\mathbf{c}}$ \\
\hline 1.80 & 1.60 & $1.00-1.80$ & 1.00 \\
1.80 & 1.50 & $1.00-1.80$ & 3.00 \\
\hline 1.50 & 1.80 & $1.00-2.10$ & 3.00 \\
1.80 & 1.80 & $1.00-2.10$ & 3.00 \\
2.10 & 1.80 & $1.00-2.10$ & 3.00 \\
2.10 & 2.10 & $1.00-2.10$ & 3.00 \\
\hline 2.30 & 1.80 & $1.00-2.10$ & 3.00 \\
\hline 2.30 & 2.30 & $1.00-2.10$ & 3.00 \\
\hline
\end{tabular}

The conditions used in the experiments are shown in Table 1. The nozzle pressure ratio, NPR, is the ratio of the stagnation pressure of the jet to the ambient pressure. The nozzle temperature ratio, NTR, is the ratio of the stagnation temperature of the jet to the ambient temperature. Subscripts $c, b$, and t refer to the core, bypass, and tertiary streams, respectively. For heated core-stream conditions, $\mathrm{NTR}_{\mathrm{b}}=\mathrm{NTR}_{\mathrm{t}}=$ 1.25. For unheated core conditions, the temperatures of the bypass and tertiary streams were also unheated. Jet conditions with $\mathrm{NPR}_{\mathrm{t}}=2.10$ produce inverted velocity profiles for the two outer jet streams. The experiments were conducted at simulated forward flight Mach numbers $\left(\mathrm{M}_{\mathrm{fj}}\right)$ of 0.0 and 0.3 . For $\mathrm{M}_{\mathrm{fj}}=0.3$, a simulated dual-stream jet, designated by $\mathrm{NPR}_{\mathrm{t}}=1.0$, was achieved by setting the third-stream conditions equal to those of the simulated flight stream.

Particle Image Velocimetry (PIV) studies included two-component measurements in a streamwise plane with the light sheet oriented along the centerline of the jet and stereo PIV measurements with a cross-stream orientation of the light sheet. The two-component measurements provided vector maps for up to 14 exit core diameters downstream of the plug tip. Stereo PIV measurements acquired data for one half of the jet and axial locations up to nine exit-core diameters downstream of the plug tip.

The stereo PIV system was configured to provide cross-stream measurements of the 3-component velocity field from the test article. The entire PIV system was mounted on a large traverse system to facilitate performing velocity plane surveys of the flow field. The entire cross-stream flow field could not be captured with sufficient spatial resolution to meet the test requirements. Hence, only the bottom half of the flow field was acquired. The Stereo PIV system employed two high-resolution $(4008 \times 2672$ pixels) cameras, mounted in landscape mode, equipped with $180 \mathrm{~mm}$ focal length lenses and $8 \mathrm{~mm}$ extension tubes to provide a $526 \times 272 \mathrm{~mm}(\mathrm{~W} \times \mathrm{H})$ field of view. The PIV system was positioned so that the top edge of the field of view was approximately $25 \mathrm{~mm}$ above the nozzle centerline. The cameras were mounted downstream of the model exit plane at nominally $\pm 45^{\circ}$ from the nozzle centerline. Stereo PIV calibrations were performed using a single plane target translated to 9 axial positions over a $\pm 2 \mathrm{~mm}$ range. A 4 th-order 
polynomial was used in the calibration and a calibration verification operation was employed to insure the calibration overlapped the laser light sheet plane. The measurement plane was illuminated with a dual head $400 \mathrm{~mJ} /$ pulse Nd:YAG laser system. The laser beams were formed into 1 by $550 \mathrm{~mm}$ light sheets using cylindrical and spherical lenses. Both cameras were connected to a single computer system via a CameraLinkTM PCI card and the 400 frame pair data sequences were acquired and streamed to disk at a rate of 2 frame-pairs/camera/sec.

In order to facilitate a large field of view and high spatial resolution in the two-component PIV measurements, a four camera, $2 \times 2$ configuration was used. The $4008 \times 2672$ pixel stereo PIV cameras were used with their 4008-pixel axis oriented vertically (portrait mode). The cameras were equipped with $180 \mathrm{~mm}$ focal length lenses and positioned so that their fields of view overlapped by $2.54 \mathrm{~cm}$. A PIV calibration target was used to calibrate and register all four cameras. The physical registration of the four cameras was used in the setup of the vector processing grids in the top-left, top-right and bottom-left and bottom-right camera images so that no interpolation was required in the merging of the left/right vector maps. The final merged camera vector map covered an area of $355 \times 560 \mathrm{~mm}(\mathrm{~W} \times \mathrm{H})$. All four cameras were connected to a single computer system via two CameraLink PCI cards and the 400 frame pair data sequences were acquired and streamed to disk at a rate of 2 frame-pairs $/$ camera $/ \mathrm{sec}$.

Four independent seeding systems were required in this study: core flow stream, bypass stream, third-stream and ambient flow. The heated core and bypass streams were seeded with $0.5 \mu \mathrm{m}$ diameter alumina powder. A dispersion of the alumina seed material in ethanol was prepared using a $\mathrm{pH}$ stabilization technique (Ref. 22). The alumina/ethanol was dispersed in the flow well upstream of the nozzle using an air-assisted atomizing nozzle. The $\mathrm{pH}$ stabilization technique provides highly dispersed, unagglomerated seed particles in the flow. The tertiary stream was also seeded using the $\mathrm{pH}$ stabilized aluminum oxide dispersion. The ambient free-jet flow was seeded using a propylene glycol liquid seed material. Several fog generators were setup in the inlet tunnel to the free-jet-allowing nearly $18 \mathrm{~m}$ of mixing before entering the PIV measurement planes.

The PIV image data were processed using multi-pass correlation with $64 \times 64$ pixel subregions on 32 pixel centers, followed by $32 \times 32$ pixel subregions on 16 pixels centers. Subregion distortion processing was also used to process the PIV data (Ref. 23). Subregion distortion was used to correct for velocity gradients across the subregion and to minimize the "peak-locking" effect, which is the tendency for the estimated particle displacements to preferentially concentrate at integer values. In the subregion distortion technique, the local velocity gradients surrounding the current correlation subregion are used to distort the subregion before the cross-correlation processing operation. Distorting the subregion yields correlation subregions with uniform particle displacements, and hence, reduces any bias caused by the velocity gradients. Typically two additional passes after the multi-pass processing are used with subregion distortion applied to refine the correlation peak estimates. Due to the oblique viewing of the model in the stereo PIV configuration, the nozzle was recorded in both the left and right camera views. The image of the nozzle corrupts the background in the image - leading to a loss of correlation in regions where the model is brightly illuminated by the laser light sheet. The Symmetric Phase Only Filtering (SPOF) technique was also applied in the data processing to mitigate any effects from the model being in the background of the images near the exit plane (Ref. 24). The final cross-stream velocity vector maps had $2 \mathrm{~mm}$ spatial resolution. The final 2-D streamwise velocity vector maps had a spatial resolution of $1.5 \mathrm{~mm}$. Sequences of 400 velocity vector maps were acquired at each measurement station and ensemble averaged to provide first and second order statistics over the entire measurement plane. Chauvenet's criteria was used to eliminate any outliers in the ensemble averaging process (Ref. 25). 


\section{Experimental Results}

\section{A. Axisymmetric Nozzle-System Results}

Three of the four tertiary nozzles produced discrete tones for some of the operating conditions in Table 1. The tones, which were not trailing edge tones (Ref. 26), were found to be the result of nozzle separations on the interior of the tertiary nozzles near the nozzle trailing edges. Roughening the nozzle surfaces with strips of sandpaper eliminated the tones as shown by the spectra in Figure 5 (where data for $140^{\circ}$ have been offset by $5 \mathrm{~dB}$ for clarity). The surface roughening may have promoted boundary layer transition. However, the sandpaper resulted in a reduction of the third-stream area and an associated reduction in broadband levels. Since the production of tones did not appear to introduce local broadband elevations, acoustic data were acquired with the untreated nozzles and tones subtracted from the resulting spectra before computing one-third-octave spectra.

The one-third-octave spectra obtained for the axisymmetric-nozzles at $\mathrm{M}_{\mathrm{fj}}=0.3, \mathrm{NPR}_{\mathrm{c}}=\mathrm{NPR}_{\mathrm{b}}=1.8$, and $\mathrm{NTR}_{\mathrm{c}}=3.0$ are shown in Figure 6 for a range of $\mathrm{NPR}_{\mathrm{t}}$. The data for $100^{\circ}$ and $140^{\circ}$ have been offset 5 and $10 \mathrm{~dB}$, respectively. For NPR $=2.1$, the velocities of the two outer streams are inverted since the tertiary-stream velocity is greater than that of the bypass stream. The introduction of the tertiary stream has little impact on low- and mid-frequency acoustic radiation at small and broadside angles $\left(60^{\circ}\right.$ and $100^{\circ}$ ) to the jet for $A_{b} / A_{c}=2.5$ and for $A_{t} / A_{c}=0.6$. At these same angles, the introduction of the tertiary stream increases low-frequency acoustic radiation for $A_{b} / A_{c}=A_{t} / A_{c}=1.0$, with increases in $N P R_{t}$ resulting in increases in noise radiation. Peak frequency shifts are also noted with the addition of the third stream for broadside angles and $A_{b} / A_{c}=A_{t} / A_{c}=1.0$. In the peak-jet-noise direction, reductions in acoustic levels at peak and mid frequencies are achieved with the introduction of a third stream for all bypass-to-core and tertiary-to-core area ratios with the largest peak-frequency reduction occurring for $\mathrm{A}_{\mathrm{b}} / \mathrm{A}_{\mathrm{c}}=2.5$ with $\mathrm{A}_{\mathrm{t}} / \mathrm{A}_{\mathrm{c}}=0.6$ and the largest mid-frequency reductions for $\mathrm{A}_{\mathrm{b}} / \mathrm{A}_{\mathrm{c}}=1.0$. Increases in highfrequency noise occur at all observation angles and for all axisymmetric nozzle configurations when the third-stream is introduced at the inverted velocity condition. Note that reductions in noise with the introduction of the third stream are accompanied by increases in ideal thrust. For $A_{b} / A_{c}=1.0, A_{t} / A_{c}=1.0$, and $\mathrm{NPR}_{\mathrm{t}}=1.3$, the ideal thrust increases by roughly 14 percent over that for the same bypass-to-core area ratio with $\mathrm{NPR}_{\mathrm{t}}=1.0$.

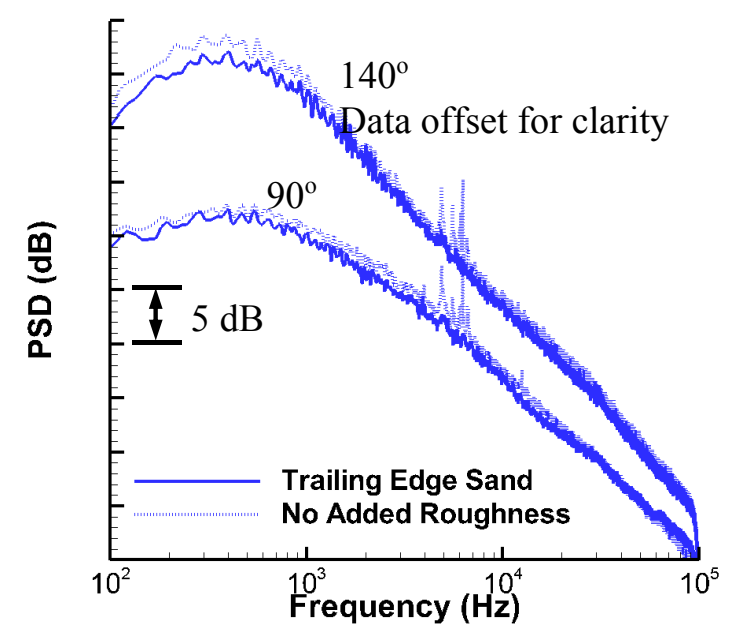

Figure 5.-The narrowband spectra acquired at the unheated conditions in Table $1, \mathrm{NPR}_{\mathrm{t}}=1.5$, and the indicated polar observation angles. 


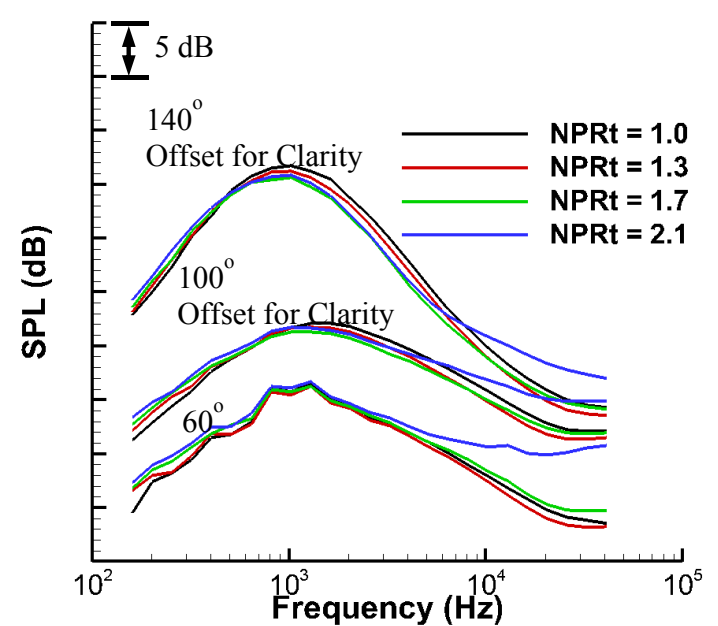

(a)

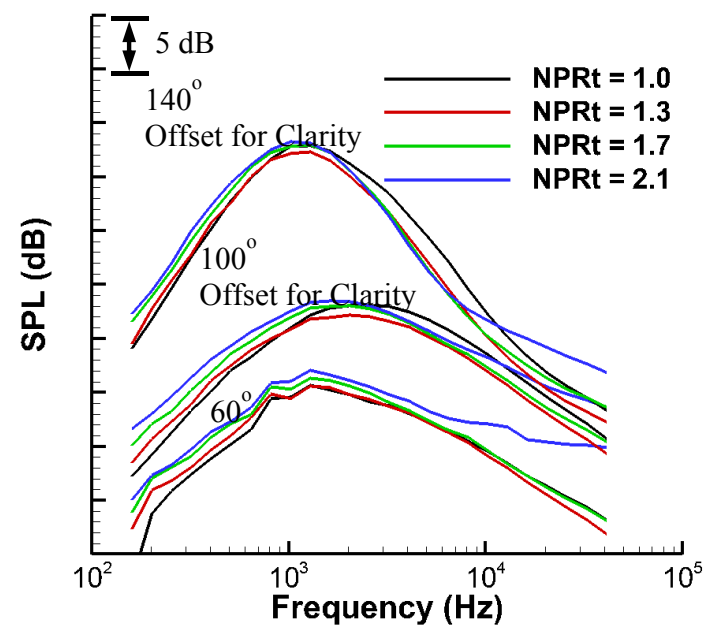

(c)

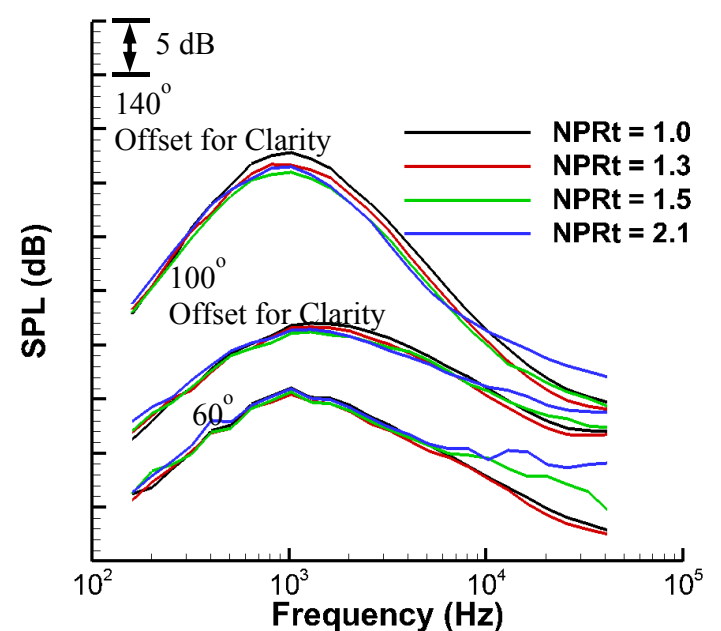

(b)

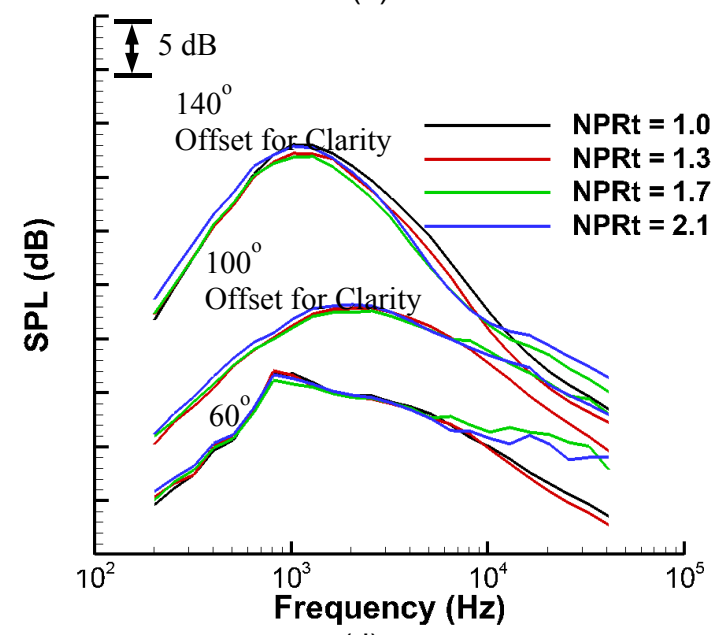

(d)

Figure 6.-The one-third-octave spectra acquired at $\mathrm{NPR}_{\mathrm{c}}=\mathrm{NPR} b=1.8, \mathrm{NTR}_{\mathrm{c}}=3.0$ and $\mathrm{M}_{\mathrm{fj}}=0.3$ for the indicated observation angles. The data are for (a) $A_{b} / A_{c}=2.5$ and $A_{t} / A_{c}=1.0$, (b) $A_{b} / A_{c}=2.5$ and $A_{t} / A_{c}=0.6$, (c) $A_{b} / A_{c}=1.0$ and $A_{t} / A_{c}=1.0$, and (d) $A_{b} / A_{c}=1.0$ and $A_{t} / A_{c}=0.6$.

The one-third-octave noise reductions, where noise reduction is given by the difference in the acoustic level for the two-stream jet $\left(\mathrm{NPR}_{\mathrm{t}}=1.0\right)$ and that of the three-stream jet, are shown in Figure 7 for the peakjet-noise direction $\left(140^{\circ}\right)$. Positive values indicate the acoustic levels of the three-stream jet are lower than those of the two stream jet. The largest noise reduction (roughly $3 \mathrm{~dB}$ ), achieved at mid frequencies, occurs for the smallest bypass-to-core area ratio, $A_{b} / A_{c}=1.0$ (Figs. 7(c) and (d)). For equivalent exit areas on the core, bypass, and tertiary streams, up to $2.5 \mathrm{~dB}$ reduction is achieved at low injection pressures $\left(\mathrm{NPR}_{\mathrm{t}}=1.3\right)$ with no increase in high-frequency noise. For $\mathrm{A}_{\mathrm{b}} / \mathrm{A}_{\mathrm{c}}=2.5$, maximum noise reduction is limited to $2 \mathrm{~dB}$ although this reduction is achieved at the peak frequency jet-noise frequency $(100 \mathrm{~Hz})$ for $A_{t} / A_{c}=0.6$ and $\mathrm{NPR}_{\mathrm{t}}=1.5$. While the results in Figure 7 indicate the maximum achievable noise reduction is relatively insensitive to tertiary-to-core area ratio, results obtained at $A_{t} / A_{c}=0.4$ show little noise reduction for all bypass-to-core area ratios within the design space shown in Figure 3 indicating the noise reduction trends in Figure 7 cannot be applied to $A_{t} / A_{c}<0.6$. 

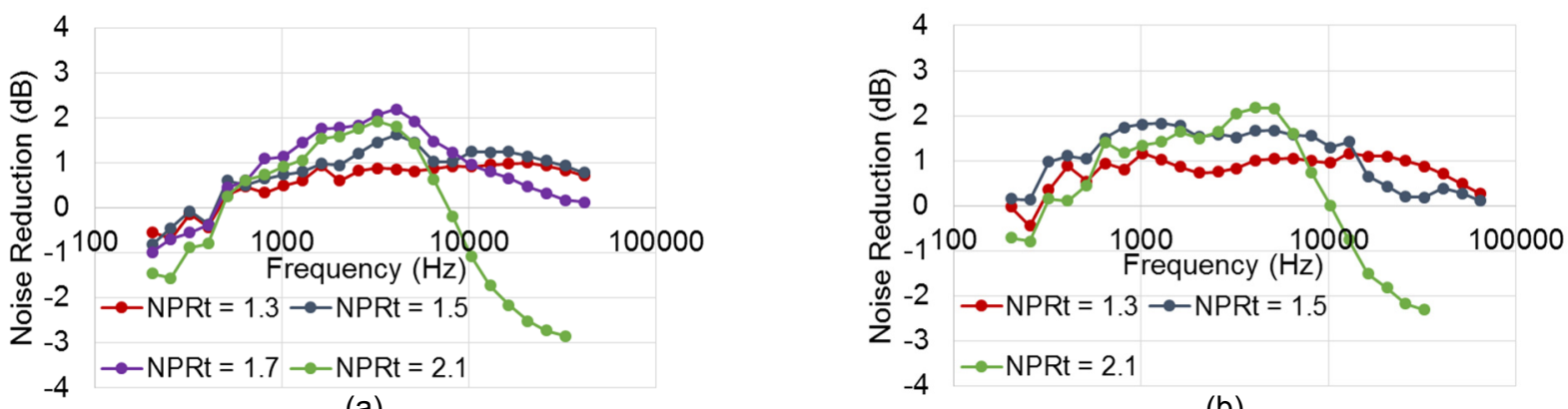

(a)

(b)

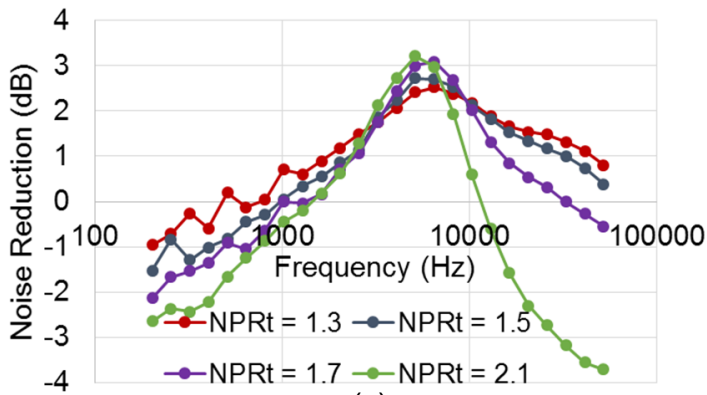

(c)

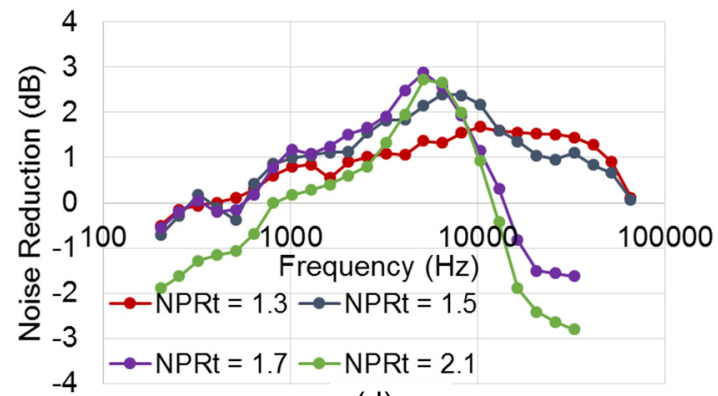

(d)

Figure 7.-The noise reduction for $\mathrm{NPR}_{\mathrm{c}}=\mathrm{NPR} b=1.8, \mathrm{NTR}_{\mathrm{c}}=3.0$ and $\mathrm{M}_{\mathrm{fj}}=0.3$ at an observation angle of $140^{\circ}$. The data are for (a) $A_{b} / A_{c}=2.5$ and $A_{t} / A_{c}=1.0$, (b) $A_{b} / A_{c}=2.5$ and $A_{t} / A_{c}=0.6$, (c) $A_{b} / A_{c}=1.0$ and $A_{t} / A_{c}=1.0$, and (d) $A_{b} / A_{c}=1.0$ and $A_{t} / A_{c}=0.6$.

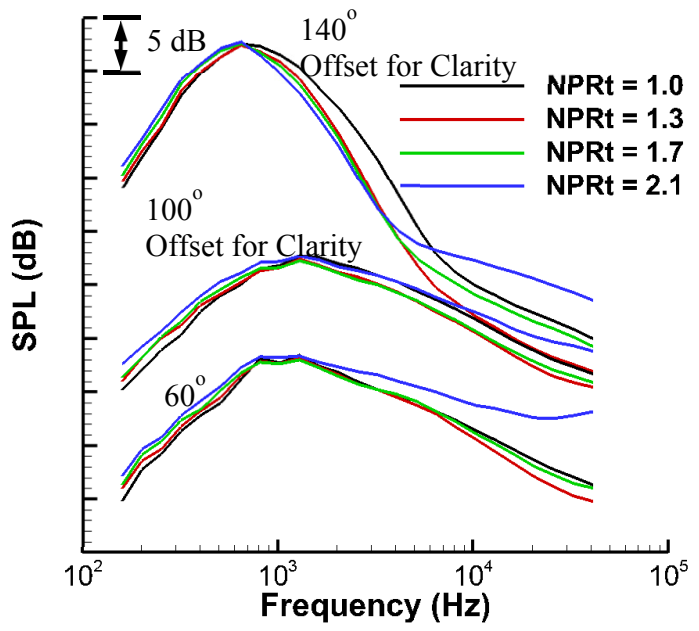

Figure 8.-The one-third-octave spectra acquired at $\mathrm{NPR}_{\mathrm{c}}=\mathrm{NPR}_{\mathrm{b}}=1.8, \mathrm{NTR}_{\mathrm{c}}=3.0$ and $\mathrm{M}_{\mathrm{fj}}=0.0$ for the indicated observation angles. The data are for $A_{b} / A_{c}=2.5$ and $A_{t} / A_{c}=1.0$.

The results obtained at $\mathrm{M}_{\mathrm{fj}}=0.0, \mathrm{NPR}_{\mathrm{c}}=\mathrm{NPR}_{\mathrm{b}}=1.8$, and $\mathrm{NTR}_{\mathrm{c}}=3.0$ for the $\mathrm{A}_{\mathrm{b}} / \mathrm{A}_{\mathrm{c}}=2.5$ and $A_{t} / A_{c}=1.0$ nozzle system are shown in Figure 8 for a range of $N_{P R}$. A comparison of the data in Figure 6(a) with that in Figure 8 indicates that, for the same three-stream area ratios and operating conditions, greater mid-frequency noise reduction in the peak-noise direction is achieved at $\mathrm{M}_{\mathrm{fj}}=0.0$ than at $\mathrm{M}_{\mathrm{fj}}=0.3$. At small and broadside angles to the jet, the impact of the third stream on acoustic radiation is similar for $\mathrm{M}_{\mathrm{fj}}=0.0$ and 0.3 . 


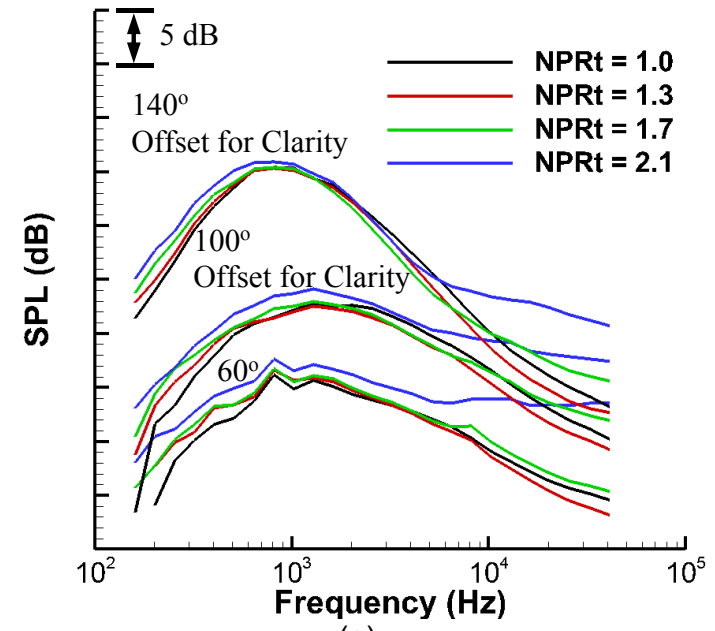

(a)

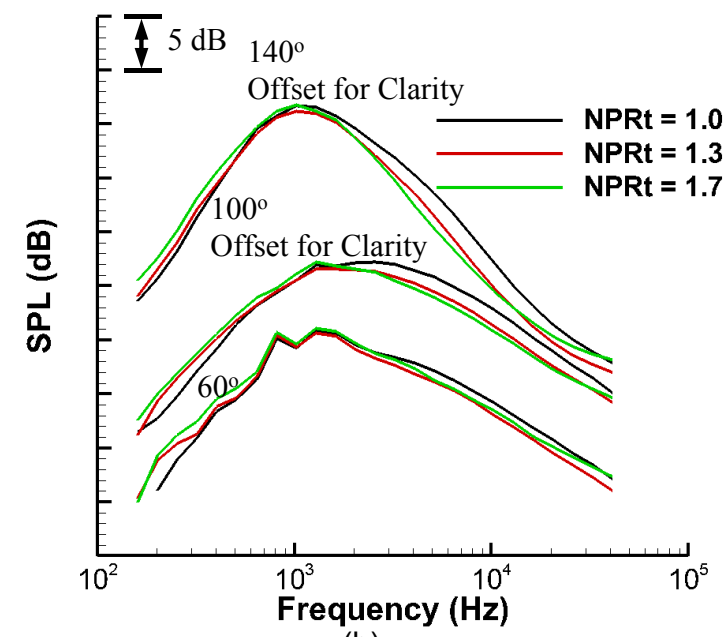

(b)

Figure 9.-The one-third-octave spectra acquired at $\mathrm{M}_{\mathrm{fj}}=0.3$ and the indicated observation angles for $A_{b} / A_{c}=2.5$ and $A_{t} / A_{c}=1.0$. The data in (a) were acquired for $N P R_{c}=1.5, N R_{b}=1.8$, and $N_{T} R_{c}=3.0$ and in (b) for $\mathrm{NPR}_{\mathrm{c}}=1.8, \mathrm{NPR}_{\mathrm{b}}=1.5, \mathrm{NTR}_{\mathrm{c}}=3.0$.

The one-third-octave spectra obtained for $\mathrm{A}_{\mathrm{b}} / \mathrm{A}_{\mathrm{c}}=2.5, \mathrm{~A}_{\mathrm{t}} / \mathrm{A}_{\mathrm{c}}=1.0$, and $\mathrm{M}_{\mathrm{fj}}=0.3$ are shown in Figure 9. The data for $\mathrm{NPR}_{\mathrm{c}}=1.5$ and $\mathrm{NPR}_{\mathrm{b}}=1.8$ are given in Figure 9(a) and for $\mathrm{NPR}_{\mathrm{c}}=1.8$ and $\mathrm{NPR}_{\mathrm{b}}$ $=1.5$ in Figure 9(b). A comparison of the data in Figures 6(a) and 9(a) shows that greater peak- and midfrequency noise reductions are achieved in the peak-jet-noise direction for a high core velocity $\left(\mathrm{NPR}_{\mathrm{c}}=\right.$ $1.8)$ than for a low core velocity $\left(\mathrm{NPR}_{\mathrm{c}}=1.5\right)$ with the introduction of the tertiary stream. For all observation angles, the increases in low-frequency acoustic radiation with increasing $\mathrm{NPR}_{\mathrm{t}}$ at low core velocity do not occur at the higher core velocity. Additionally, increasing $\mathrm{NPR}_{t}$ produces larger increases in high-frequency noise for the low core velocity than the higher core velocity. A comparison of the results in Figures 6(a) and 9(b) shows the addition of the third stream produces similar noise reduction characteristics in the peak-jet-noise direction for the same core velocity although, at the same $\mathrm{NPR}_{\mathrm{t}}$, a slightly greater peak-frequency reduction is achieved for the higher fan velocity $\left(\mathrm{NPR}_{b}=1.8\right)$ than the lower fan velocity $\left(\mathrm{NPR}_{\mathrm{b}}=1.5\right)$ and slightly greater mid-frequency reductions are achieved for the lower fan velocity than the higher fan velocity. At broadside angles $\left(100^{\circ}\right)$, the introduction of the third stream has a greater impact on noise reduction at peak- and mid-frequency noise for $\mathrm{NPR}_{\mathrm{b}}=1.5$ than for $\mathrm{NPR}_{\mathrm{b}}=$ 1.8. At small observation angles $\left(60^{\circ}\right)$, the impact of the tertiary stream on the resulting acoustic radiation appears to be insensitive to bypass-stream conditions.

\section{B. Insert Nozzle-System Results}

The results obtained with the tertiary-nozzle inserts for $A_{b} / A_{c}=2.5$ are shown in Figure 10 for $\mathrm{NPR}_{\mathrm{c}}=\mathrm{NPR}_{\mathrm{b}}=1.8, \mathrm{NTR}_{\mathrm{c}}=3.0$, and $\mathrm{M}_{\mathrm{fj}}=0.3$. The data in Figures 10(a) and (b) were acquired with the insert located (and centered) on the side of the jet closest to the microphone array and on the side of the jet opposite to the microphone array, respectively. For both insert orientations, the introduction of the third stream at NPR $\geq 1.7$ increased acoustic radiation at all observation angles. For $\mathrm{NPR}_{t}=1.3$, the introduction of the tertiary stream with the insert-nozzle system had only a slight impact on acoustic radiation. Data acquired for other third-stream area ratios (using inserts with less circumferential blockage than that shown in Figure 4(b)) produced trends similar to those in Figure 10. 


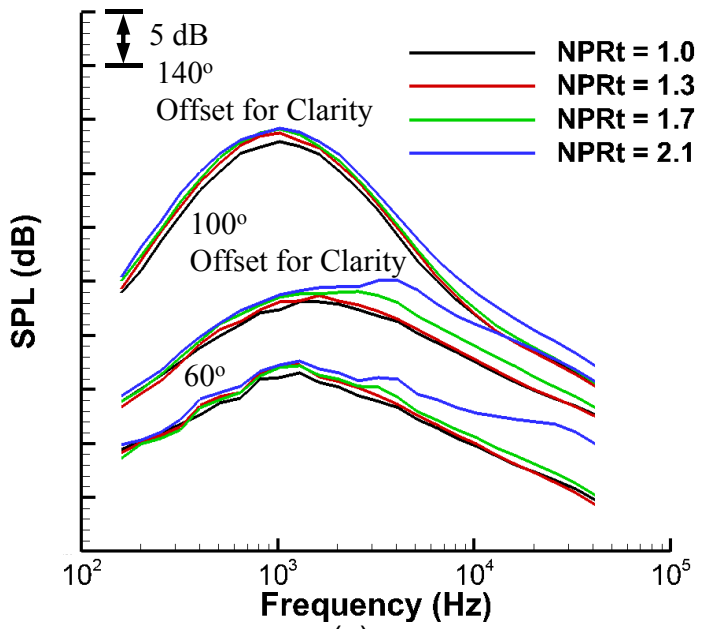

(a)

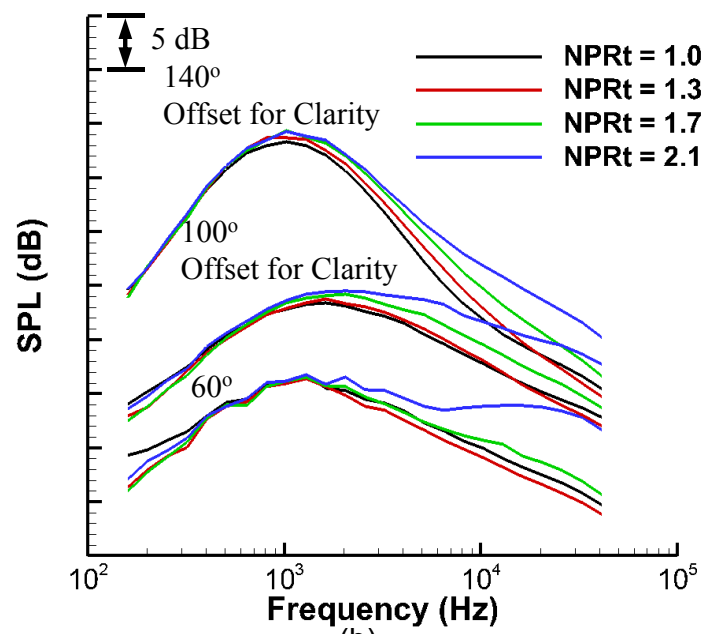

(b)

Figure 10.-The one-third-octave spectra acquired at $\mathrm{NPR}_{\mathrm{c}}=\mathrm{NPR}_{\mathrm{b}}=1.8, \mathrm{NTR}_{\mathrm{c}}=3.0$ and $\mathrm{M}_{\mathrm{fj}}=0.3$ for the indicated observation angles using the third-stream nozzle insert and $A_{b} / A_{c}=2.5$. The data in (a) and (b) were obtained with the insert located on the side of the jet closest to the microphone array and on the side of the jet opposite to the microphone array, respectively.

\section{Offset Duct Nozzle-System Results}

The results for the offset-duct nozzle configuration obtained at $\mathrm{M}_{\mathrm{fj}}=0.3, \mathrm{NPR}_{\mathrm{c}}=\mathrm{NPR}_{\mathrm{b}}=1.8$, and $\mathrm{NTR}_{\mathrm{c}}=3.0$ are shown in Figure 11. In Figures 11(a) and (c), the thick side of the tertiary nozzle (Fig. 4(a)) is on the side of the jet closest to the microphone array. In Figures 11(b) and (d), the thin side of the tertiary nozzle is on the side of the jet closest to the microphone array. For $A_{b} / A_{c}=2.5$, increasing $\mathrm{NPR}_{t}$ reduces peak- and mid-frequency acoustic radiation in the peak-jet-noise direction and increases low- and high-frequency radiation at small and broadside angles on the thick side of the jet (Fig. 11(a)). On the thin side of the jet (Fig. 11(b)), the introduction of the third stream at $\mathrm{NPR}_{\mathrm{t}}<2.1$ has little impact on acoustic radiation in the peak-jet-noise direction and a similar impact on acoustic radiation to that for the thick side of the jet at small and broadside angles to the jet. Mid-frequency noise reduction in the peak-jet-noise direction on the thick side of the jet is slightly greater with the introduction of the third stream for $A_{b} / A_{c}=1.0$ (Fig. 11(c)) than for the same $N P R_{t}$ and $A_{b} / A_{c}=2.5$. At small and broadside angles to the jet, increasing $\mathrm{NPR}_{\mathrm{t}}$ results in greater increases in low- and mid-frequency acoustic radiation on the thick side of the jet for $A_{b} / A_{c}=1.0$ than for $A_{b} / A_{c}=2.5$. On the thin side of the jet, the introduction of the third stream increases acoustic radiation at all frequencies and all observation angles for $A_{b} / A_{c}=1.0$. For all area ratios and observation angles, the addition of the third stream at the inverted velocity condition results in elevated high-frequency levels.

The one-third-octave spectra for the offset-duct nozzle system and supersonic core conditions (Table 1) are shown in Figure 12 for $\mathrm{A}_{\mathrm{b}} / \mathrm{A}_{\mathrm{c}}=2.5$. All data have been acquired with the thick side of the nozzle closest to the microphone array. The data for $100^{\circ}$ and $140^{\circ}$ have been offset by 5 and $10 \mathrm{~dB}$, respectively, in Figures 12(a) to (c) and by 7 and $15 \mathrm{~dB}$, respectively, in Figure 12(d). The circled regions indicate the presence of broadband shock associated noise. In the peak-jet-noise direction, noise reduction resulting from the addition of the third stream decreases with increasing $\mathrm{NPR}_{\mathrm{b}}$ for the same core and tertiary conditions and increases with increasing $\mathrm{NPR}_{\mathrm{c}}$ for the same bypass and tertiary conditions. The largest noise reductions in the peak-jet-noise direction for the supersonic core conditions (Figs. 12(a) and (c)) are greater than those for the same bypass condition and subsonic core flow (Fig. 11(a)). The addition of the third stream at $\mathrm{NPR}_{\mathrm{t}}<2.1$ has little impact on acoustic radiation at small and broadside angles for all supersonic conditions and $\mathrm{NPR}_{\mathrm{b}}=1.8$. For $\mathrm{NPR}_{\mathrm{b}}=2.3$ (Fig. $12(\mathrm{~d})$ ), the addition of the third stream increases broadband-shock noise levels. 


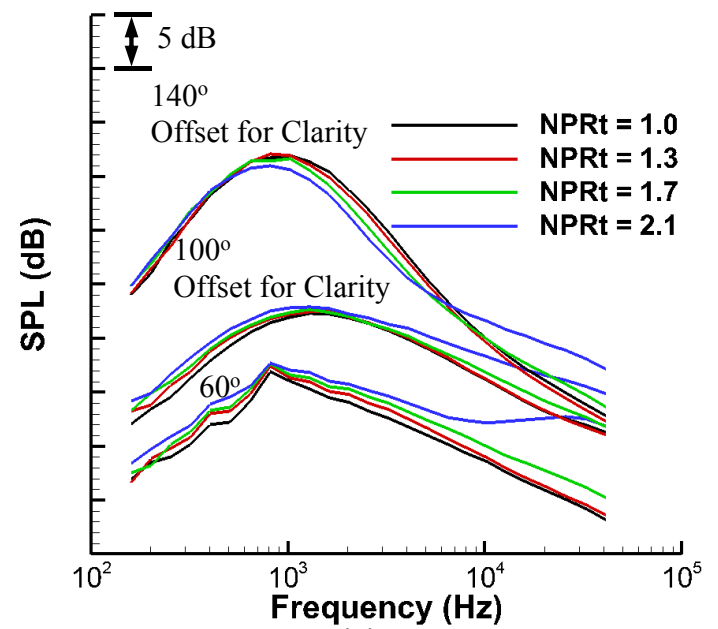

(a)

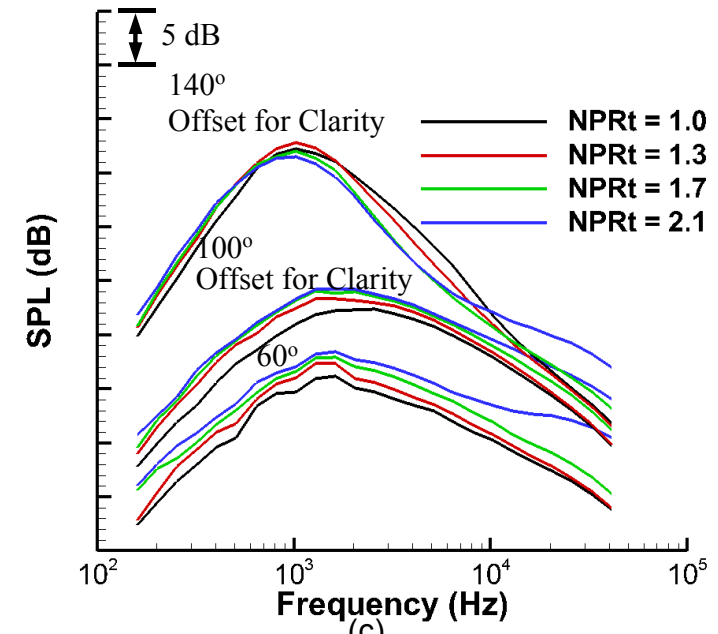

(c)

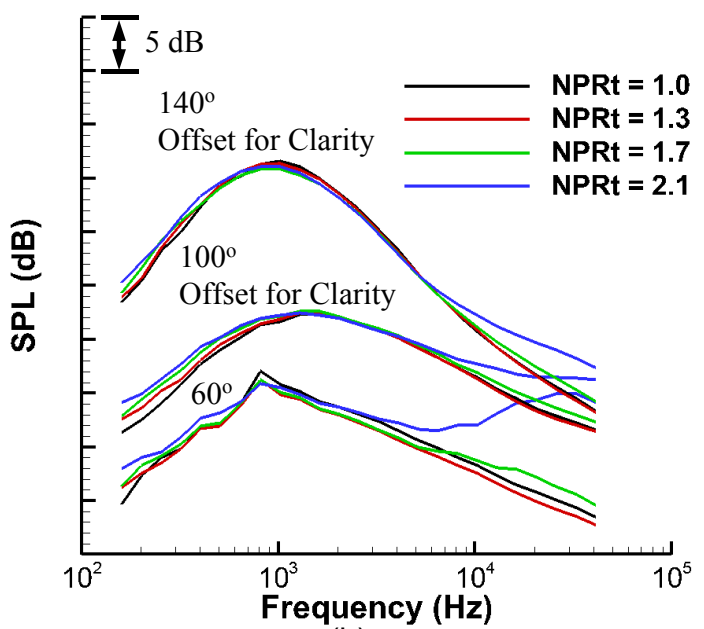

(b)

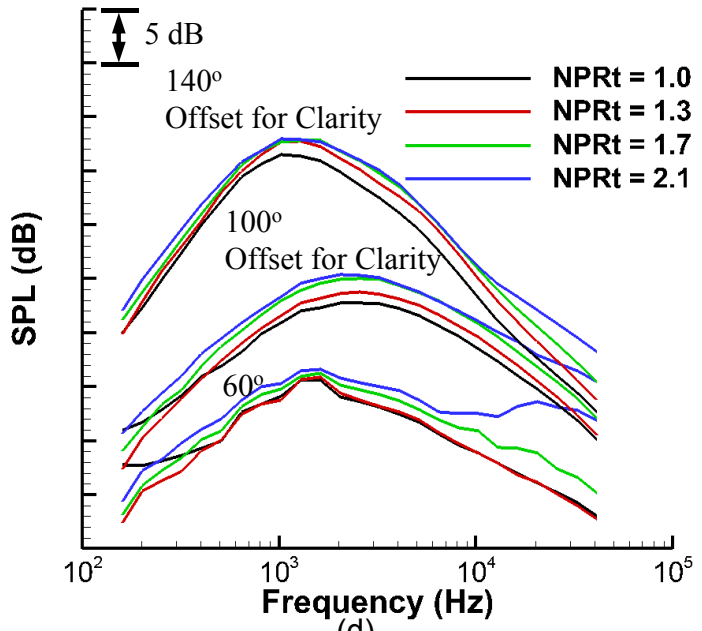

(d)

Figure 11.-The one-third-octave spectra acquired at $\mathrm{NPR}_{\mathrm{c}}=\mathrm{NPR}_{\mathrm{b}}=1.8, \mathrm{NTR}_{\mathrm{c}}=3.0$ and $\mathrm{M}_{\mathrm{fj}}=0.3$ for the indicated observation angles using the tertiary-nozzle offset duct. The data in (a) and (b) were obtained with $A_{b} / A_{c}=2.5$ and in (c) and (d) with $A_{b} / A_{c}=1.0$. For (a) and (c) the thick side of the jet is closest to the microphone array. In (b) and (d), the thin side of the jet is closest to the microphone array. 


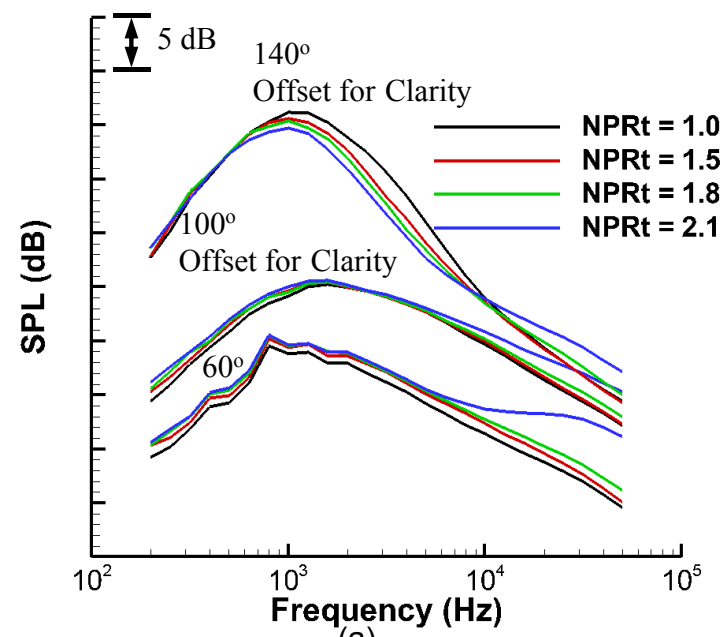

(a)

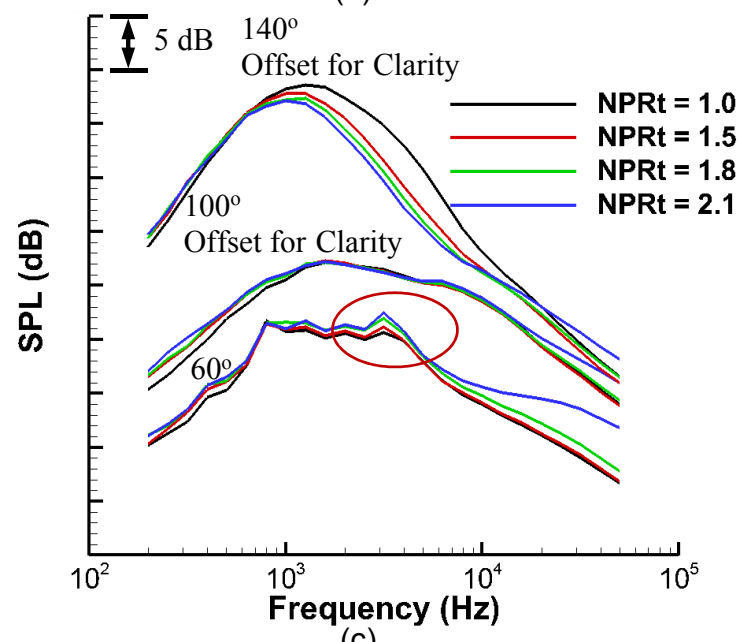

(c)

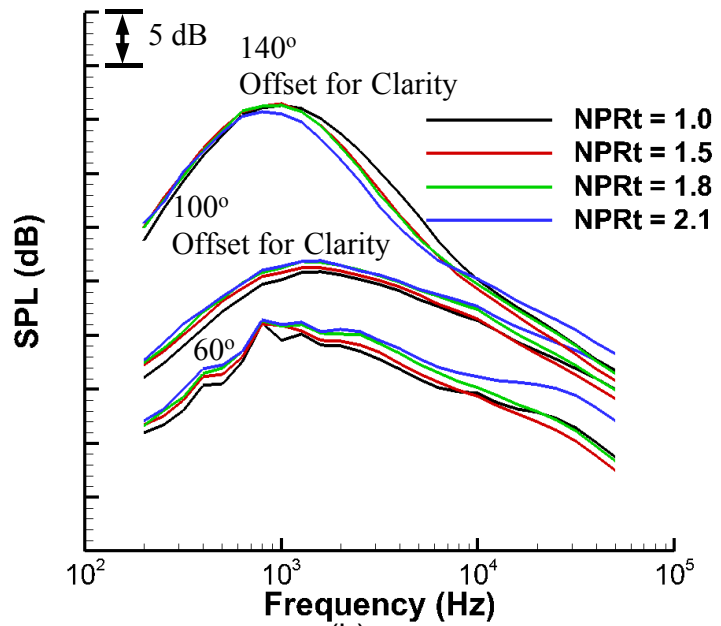

(b)

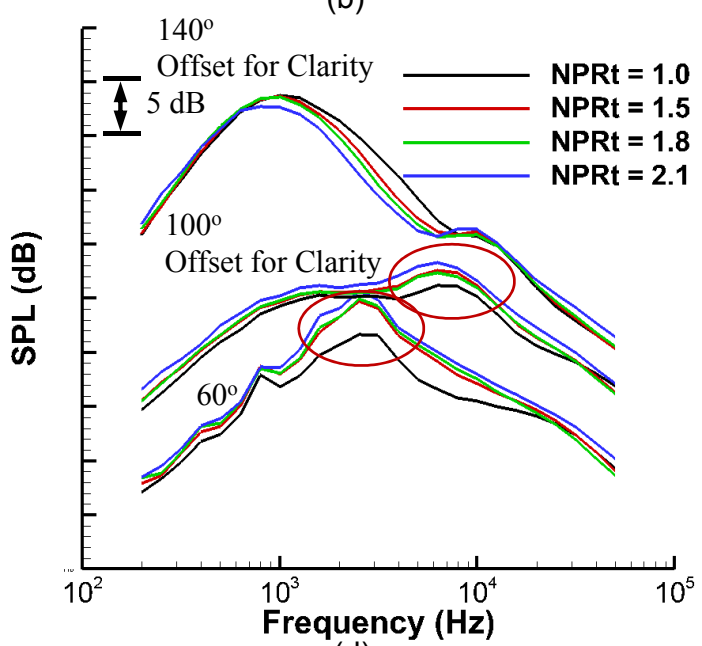

(d)

Figure 12.-The one-third-octave spectra on the thick side of the offset-duct nozzle system with $A_{b} / A_{c}=2.5$ for $\mathrm{NTR}_{\mathrm{c}}=3.0$ and $\mathrm{M}_{\mathrm{fj}}=0.3$. The data are for $(\mathrm{a}) \mathrm{NPR}_{\mathrm{c}}=2.1$ and $\mathrm{NPR}_{\mathrm{b}}=1.8$, (b) NPR $\mathrm{c}=2.1$ and $\mathrm{NPR}_{\mathrm{b}}=2.1$, (c) $\mathrm{NPR}_{\mathrm{c}}=2.3$ and $\mathrm{NPR}_{\mathrm{b}}=1.8$, and $(\mathrm{d}) \mathrm{NPR}_{\mathrm{c}}=2.3$ and $\mathrm{NPR}_{\mathrm{b}}=2.3$. 


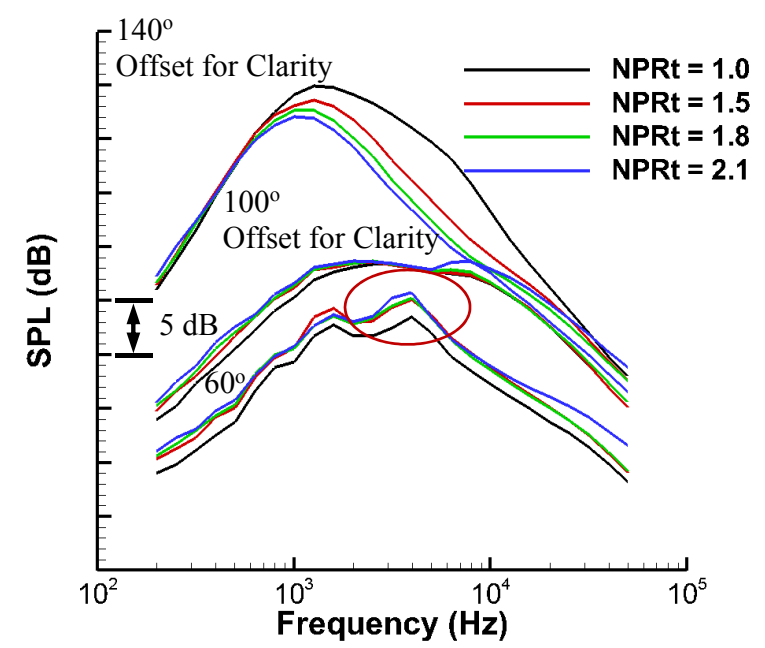

Figure 13.-The one-third-octave spectra on the thick side of the offset-duct nozzle system acquired with $\mathrm{A}_{b} / \mathrm{A}_{\mathrm{c}}=1.0, \mathrm{NPR} \mathrm{C}=2.3, \mathrm{NPR}_{\mathrm{b}}=1.8, \mathrm{NTR}_{\mathrm{c}}=3.0$, and $\mathrm{M}_{\mathrm{fj}}=0.3$.

The results obtained for the offset-duct nozzle system and $A_{b} / A_{c}=1.0$ are shown in Figure 13 for $\mathrm{NPR}_{\mathrm{c}}=2.3, \mathrm{NPR}_{\mathrm{b}}=1.8, \mathrm{NTR}_{\mathrm{c}}=3.0$, and $\mathrm{M}_{\mathrm{fj}}=0.3$. The data have been acquired with the thick side of the nozzle closest to the microphone array. A comparison of Figures 12(c) and 13 show that greater noise reduction is achieved in the peak-jet-noise direction with the addition of the third stream for $A_{b} / A_{c}=1.0$ than for $A_{b} / A_{c}=2.5$. At small and broadside observation angles, the addition of the third stream increases broadband-shock noise levels for $\mathrm{A}_{\mathrm{b}} / \mathrm{A}_{\mathrm{c}}=1.0$.

The one-third-octave noise reductions in the peak-jet-noise direction on the thick side of the offset duct are shown in Figure 14 for the supersonic core conditions in Table 1. The data for $A_{b} / A_{c}=1.0$ and $\mathrm{A}_{\mathrm{b}} / \mathrm{A}_{\mathrm{c}}=2.5$ are indicated with dashed and solid lines, respectively. For $\mathrm{A}_{\mathrm{b}} / \mathrm{A}_{\mathrm{c}}=2.5$, the peak frequency band for $140^{\circ}$ at $\mathrm{NPR}_{\mathrm{t}}=1.0$ is $1000 \mathrm{~Hz}$ for the core and bypass exhaust conditions used in Figure 14. The results in Figure 14 indicate maximum noise reduction resulting from the addition of the offset tertiary stream occurs at frequencies above the peak frequency for the simulated two-stream jet. For all core and bypass conditions, maximum noise reduction occurs for $\mathrm{NPR}_{\mathrm{t}}=2.1$ and is accompanied by highfrequency noise increases. For the same bypass, core, and tertiary conditions, maximum noise reduction for $A_{b} / A_{c}=1.0$ is greater than that for $A_{b} / A_{c}=2.5$. Noise reduction of up to $8 \mathrm{~dB}$ is achieved for $\mathrm{NPR}_{c}=$ $2.3, \mathrm{NPR}_{\mathrm{b}}=1.8$, and $\mathrm{NPR}_{\mathrm{t}}=2.1$.

The experimental results were used to develop a one-third-octave-band noise-reduction model for acoustic radiation on the thick side of the jet given by

$$
N R_{1 / 3}=\beta_{o}+\beta_{1} x_{1}+\beta_{2} x_{2}+\beta_{3} x_{3}+\beta_{4} x_{4}+\beta_{5} x_{2}^{2}+\beta_{6} x_{2} x_{3}+\beta_{7} x_{3} x_{4}+\beta_{8} x_{2} x_{4},
$$

where $N R_{1 / 3}$ is the noise reduction in one-third-octave bands and $\beta_{n}, n=0, \cdots, 8$ are coefficients determined from the method of least squares. The values for $x_{1}, x_{2}, x_{3}$ and $x_{4}$ are given by the centered and standardized values of $\mathrm{A}_{\mathrm{b}} / \mathrm{A}_{\mathrm{c}}, \mathrm{NPR}_{\mathrm{t}}, \mathrm{NPR}_{\mathrm{c}}$, and $\mathrm{NPR}_{\mathrm{b}}$. Centered and standardized values shift and scale the quantities used in the experiments to fit a span of -1 to 1 . For the bypass-to-core area ratio, $\mathrm{A}_{\mathrm{b}} / \mathrm{A}_{\mathrm{c}}=1.0$ becomes -1.0 and $\mathrm{A}_{\mathrm{b}} / \mathrm{A}_{\mathrm{c}}=2.5$ becomes 1.0. The model, developed for the supersonic core conditions in Table 1, used centered and standardized values for the nozzle-pressure-ratio terms based on values for NPR $\mathrm{R}_{\mathrm{t}}$ between 1.5 and 2.1, NPR between 2.1 and 2.3, and $\mathrm{NPR}_{\mathrm{b}}$ between 1.8 and 2.3. The last three terms in the equation represent interaction terms. The inclusion of interaction terms indicates that the impact of increasing the level of one variable in the interaction term on the resulting noise reduction 
depends on the level of the other variable in the interaction term. The resulting coefficients are shown in Figure 15 for a range of observation angles. The values of $\beta_{o}$ indicate that noise reduction increases with increasing polar angle. Increasing the level of $A_{b} / A_{c}$ (the $\beta_{1}$ term) reduces the maximum noise reduction at large angles to the jet inlet axis $\left(160^{\circ}\right)$. Increasing the level of $\mathrm{NPR}_{\mathrm{t}}$ (the $\beta_{2}$ term) increases peak-noise reduction at large angles to the jet inlet axis $\left(130^{\circ}\right.$ to $\left.160^{\circ}\right)$ and increases high-frequency acoustic radiation at all polar angles. Increasing $\mathrm{NPR}_{\mathrm{c}}$ (the $\beta_{3}$ term) increases mid-frequency acoustic radiation in the peak direction. Increasing $\mathrm{NPR}_{\mathrm{b}}$ decreases mid-frequency radiation in the peak direction and increases high-frequency radiation at small observation angles. The interaction and quadratic terms impact noise reduction at high frequencies.

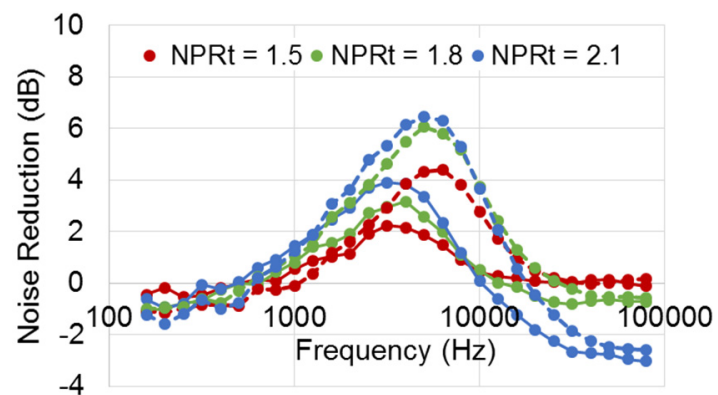

(a)

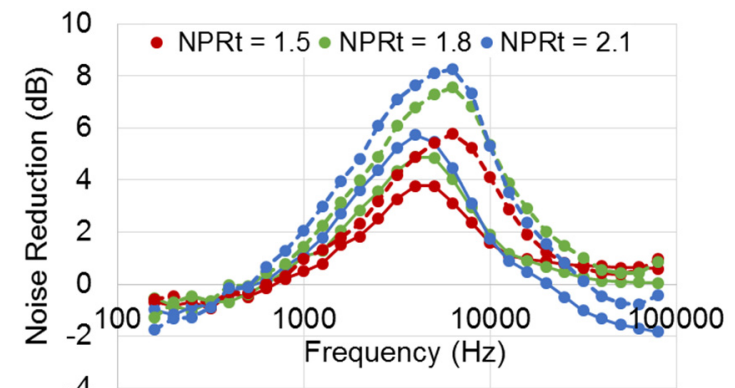

(c)

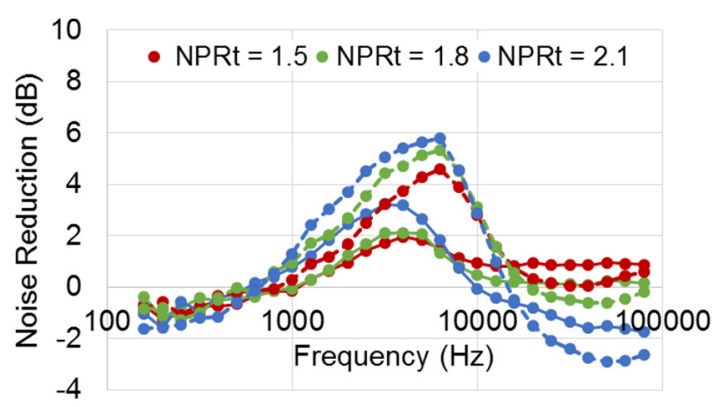

(b)

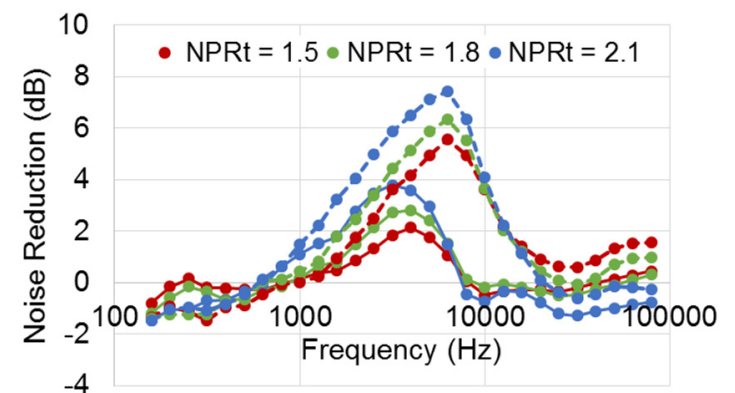

(d)

Figure 14.-The one-third-octave band noise reduction on the thick side of the offset-duct-nozzle in the peak-jetnoise direction $\left(140^{\circ}\right)$ for $(a) N^{2} R_{c}=2.1$ and $N P R_{b}=1.8$, (b) NPR $=2.1$ and $N P R_{b}=2.1$, (c) $N P R_{c}=2.3$ and $N P R_{b}=1.8$, and $(d) N P R_{c}=2.3$ and $N P R_{b}=2.3$. All data were acquired with $N T R_{c}=3.0$ and $\mathrm{Mf}_{j}=0.3$. Dashed and solid lines are for $A_{b} / A_{c}=1.0$ and $A_{b} / A_{c}=2.5$, respectively. 

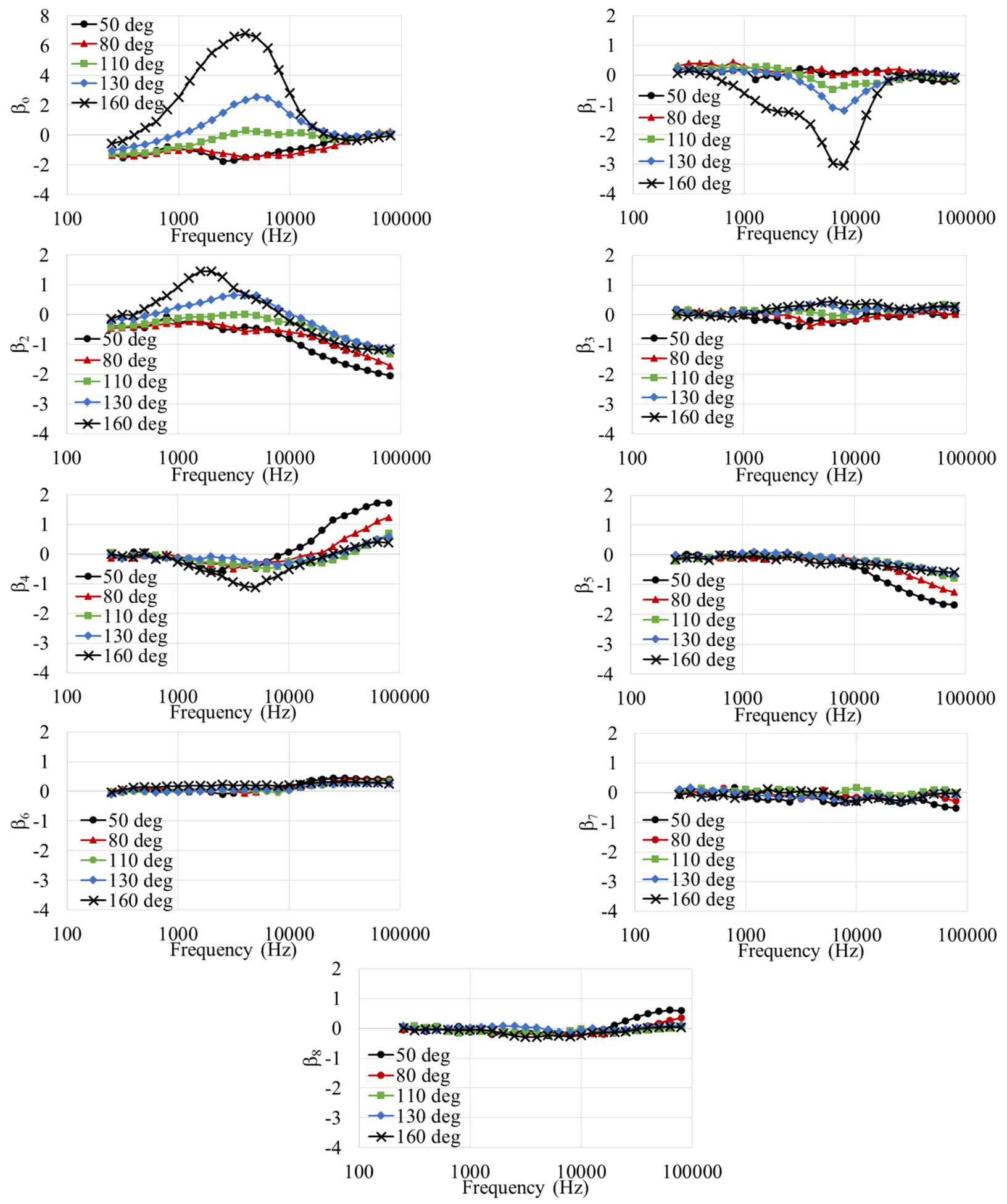

Figure 15.-The one-third-octave band noise reduction coefficients for the thick side of the offset-duct nozzle system. The polar angles are indicated in each plot. 


\section{Acoustic Analogy}

\section{A. Basic Equations}

The noise prediction method used in this paper is based on the generalized acoustic analogy of Goldstein (Ref. 27), which has been used to develop noise prediction methods for round, cold jets by Goldstein and Leib (Ref. 3), Leib and Goldstein (Ref. 28), and for rectangular jets by Leib (Ref. 29).

Goldstein and Leib (Ref. 3 ) show that the acoustic spectrum at $\boldsymbol{x}$ due to a unit volume of turbulence at $\boldsymbol{y}$ is given by

$$
I_{\omega}(\boldsymbol{x} \mid \boldsymbol{y})=(2 \pi)^{2} \Gamma_{\lambda j}(\boldsymbol{x} \mid \boldsymbol{y} ; \omega) \int_{V} \Gamma_{\kappa l}^{*}(\boldsymbol{x} \mid \boldsymbol{y}+\boldsymbol{\eta} ; \omega) \boldsymbol{Z}_{\lambda j \kappa l}(\boldsymbol{y}, \boldsymbol{\eta}, \omega) d \boldsymbol{\eta}
$$

where the Greek indices range from one to four and the Latin indices from one to three, an asterisk denotes the complex conjugate, $\Gamma_{\lambda j}$ is the Fourier transform of a propagator function, and $\mathbb{Z}_{\lambda j \kappa l}$ is the source spectrum.

The propagator function is defined as

$$
\Gamma_{\lambda j}(\boldsymbol{x} \mid \boldsymbol{y} ; \omega) \equiv \frac{1}{2 \pi} \int_{-\infty}^{\infty} e^{i \omega(t-\tau)} \gamma_{\lambda j}(\boldsymbol{x} \mid \boldsymbol{y}, t-\tau) d(t-\tau),
$$

where

$$
\gamma_{\lambda j}(\boldsymbol{x}, t \mid \boldsymbol{y}, \tau) \equiv \frac{\partial g_{\lambda 4}^{a}(\boldsymbol{y}, \tau \mid \boldsymbol{x}, t)}{\partial y_{j}}-(\gamma-1) \delta_{\lambda k} \frac{\partial \tilde{v}_{k}}{\partial y_{j}} g_{44}^{a}(\boldsymbol{y}, \tau \mid \boldsymbol{x}, t),
$$

with $\gamma$ being the ratio of specific heats, $\tilde{v}_{k}$ the Favre-averaged velocity, and $g_{\lambda 4}^{a}(\boldsymbol{y}, \tau \mid \boldsymbol{x}, t)$ the fourth component of the adjoint vector Green's function, which can be calculated from Equations (4.8) to (4.11) of Reference 3 once the mean flow is specified.

The source spectrum $\mathbb{Z}_{j \kappa l}$ in Equation (2) is related to the spectrum of the generalized Reynolds stress auto-covariance tensor,

$$
H_{\lambda j \kappa l}(\boldsymbol{y}, \boldsymbol{\eta}, \omega)=\frac{1}{2 \pi} \int_{-\infty}^{\infty} e^{-i \omega \tau} R_{\lambda j \kappa l}(\boldsymbol{y}, \boldsymbol{\eta}, \tau) d \tau,
$$

with

$$
R_{\lambda j \kappa l}(\boldsymbol{y}, \boldsymbol{\eta}, \tau) \equiv \overline{\left[\rho v_{\lambda}^{\prime} v_{j}^{\prime}-\overline{\rho v_{\lambda}^{\prime} v_{j}^{\prime}}\right]\left(\boldsymbol{y}, \tau_{0}\right)\left[\rho v_{\kappa}^{\prime} v_{l}^{\prime}-\overline{\rho v_{\kappa}^{\prime} v_{l}^{\prime}}\right]\left(\boldsymbol{y}+\boldsymbol{\eta}, \tau_{0}+\tau\right)}
$$


where $v_{\lambda}^{\prime} \equiv v_{\lambda}-\tilde{v}_{\lambda}$ denotes a generalized, four-dimensional 'velocity` fluctuation, with $v_{i}, i=1,2,3$ being the ordinary fluid velocity and $v_{4} \equiv(\gamma-1)\left(h^{\prime}+\frac{1}{2} v^{\prime 2}\right)$, where $h^{\prime}$ is the fluctuating enthalpy, and an overbar represents time average, by the simple linear transformation

$$
\#_{\lambda j \kappa l}=\varepsilon_{\lambda j, \sigma m} H_{\sigma m \mu n} \varepsilon_{\kappa l, \mu n},
$$

where

$$
\varepsilon_{\lambda j, \sigma m} \equiv \delta_{\lambda \sigma} \delta_{j m}-\frac{\gamma-1}{2} \delta_{\lambda j} \delta_{\sigma m}
$$

The acoustic spectrum is obtained upon integrating $I_{\omega}(\boldsymbol{x} \mid \boldsymbol{y})$ over the volume of the jet

$$
I_{\omega}(\boldsymbol{x})=\int_{V} I_{\omega}(\boldsymbol{x} \mid \boldsymbol{y}) d \boldsymbol{y}
$$

\section{B. Green's Function}

For the noise predictions in this paper, the mean flow is represented by a unidirectional transversely shear mean flow

$$
\tilde{v}_{i}=\delta_{i 1} U\left(y_{2}, y_{3}\right), \widetilde{c^{2}}=\widetilde{c^{2}}\left(y_{2}, y_{3}\right), \bar{p}=\text { constant }
$$

for which the adjoint vector Green's function can be expressed in terms of a single scalar function. For observer locations in the far field, the relevant problem for the Green's function can be expressed in polar coordinates(Ref. 30) as

$$
\frac{\partial^{2} g}{\partial y_{T}^{2}}+\frac{1}{y_{T}} \frac{\partial g}{\partial y_{T}}+\frac{1}{y_{T}^{2}} \frac{\partial^{2} g}{\partial \varphi_{0}^{2}}+\mathbb{R} \frac{\partial g}{\partial y_{T}}+7 \frac{1}{y_{T}} \frac{\partial g}{\partial \varphi_{0}}+\omega^{2} \sharp g=0
$$

where

$$
\begin{aligned}
& \boldsymbol{R}\left(y_{T}, \varphi_{0}\right)=\left\{\frac{2 \cos \vartheta}{\left[1-M\left(\boldsymbol{y}_{T}\right) \cos \vartheta\right]} \frac{\partial M\left(\boldsymbol{y}_{T}\right)}{\partial y_{T}}+\frac{1}{\widetilde{c^{2}}\left(\boldsymbol{y}_{T}\right)} \frac{\partial \widetilde{c^{2}}\left(\boldsymbol{y}_{T}\right)}{\partial y_{T}}\right\}, \\
& \boldsymbol{\mathcal { F }}\left(y_{T}, \varphi_{0}\right)=\left\{\frac{2 \cos \vartheta}{\left[1-M\left(\boldsymbol{y}_{T}\right) \cos \vartheta\right]} \frac{\partial M\left(\boldsymbol{y}_{T}\right)}{y_{T} \partial \varphi_{0}}+\frac{1}{\widetilde{c^{2}}\left(\boldsymbol{y}_{T}\right)} \frac{\partial \widetilde{c^{2}}\left(\boldsymbol{y}_{T}\right)}{y_{T} \partial \varphi_{0}}\right\}
\end{aligned}
$$

and

$$
\boldsymbol{\#}\left(y_{T}, \varphi_{0}\right)=\left\{\frac{\left[1-M\left(\boldsymbol{y}_{T}\right) \cos \vartheta\right]^{2}}{\widetilde{c^{2}}\left(\boldsymbol{y}_{T}\right)}-\frac{\cos ^{2} \vartheta}{c_{\infty}^{2}}\right\},
$$


with $M\left(\boldsymbol{y}_{T}\right)=U\left(\boldsymbol{y}_{T}\right) / c_{\infty}$ being the acoustic Mach number, $c_{\infty}$ the ambient sound speed and $\widetilde{c^{2}}\left(\boldsymbol{y}_{T}\right)$ the mean sound speed squared, subject to the far-field boundary condition

$$
g\left(y_{T}, \varphi_{0} ; \varphi, \vartheta: \omega\right) \rightarrow \frac{\left(\omega / c_{\infty}\right)^{2} e^{-i \omega / c_{\infty} \sin \vartheta y_{T} \cos \left(\varphi-\varphi_{0}\right)} e^{i \pi / 4}}{2(2 \pi)^{2} \sqrt{2 \pi \sin \vartheta \omega / c_{\infty}}}+\text { outgoing waves }
$$

as $y_{T}=\left|\boldsymbol{y}_{T}\right|=\sqrt{y_{2}^{2}+y_{3}^{2}} \rightarrow \infty$, where $\vartheta=\cos ^{-1}\left(x_{1} / x\right)(x=|\boldsymbol{x}|)$ is the observer polar angle measured relative to the downstream jet axis, $\varphi=\tan ^{-1}\left(x_{3} / x_{2}\right)$ the observer azimuthal angle and $\varphi_{0}=\tan ^{-1}\left(y_{3} / y_{2}\right)$. Noise prediction results will be presented in terms of the observer polar angle measured relative to the nozzle inlet, $\theta=180^{\circ}-\vartheta$.

For the non-axisymmetric mean flows considered in this paper, the approach of Leib (Ref. 30) is used to obtain the Green's function. The approach consists of expanding the coefficients in Equation (11), and the solution, $g$, in terms of their azimuthal Fourier coefficients, approximating the transverse derivatives by second-order finite differences and solving the resulting banded system of algebraic equations using a sparse system algorithm. Further details of the numerical methods can be found in Reference 30 .

\section{Source Model}

The source model used in this work is the hybrid (space-time/spectral) model of Leib and Goldstein (Ref. 28). This model was constructed with the time and streamwise separation dependence of the Reynolds stress auto-covariance tensor, (Eq. (6)), represented by a functional form accounting for experimentally observed features of this quantity, and the transverse separation dependence specified in terms of a frequency-dependent length scale that enters through its spectrum. The approach was referred to as a hybrid one, to signify the combined used of space-time and wavenumber-frequency domain modeling.

The model provides a formula for the source spectral function,

$$
\Psi_{\lambda j \kappa l}^{*}(\boldsymbol{y} ; \boldsymbol{k}, \omega) \equiv \int_{V} e^{i(\boldsymbol{k} \cdot \boldsymbol{\eta})} H_{\lambda j k l}(\boldsymbol{y}, \boldsymbol{\eta}, \omega) d \boldsymbol{\eta},
$$

as (Ref. 28)

$$
\Psi *_{\lambda j k l}\left(k_{1}, k_{T}, \omega\right)=-\frac{\pi l_{0} l_{1} \bar{l}_{T}^{2}\left(1+\tilde{\omega}^{2}\right)^{1 / 2}}{U_{c}} \sum_{m, l=0}^{\infty} a_{m, l}(-1)^{m+l} D_{k_{1}}^{m} D_{\omega}^{l} \frac{1}{R} \frac{\partial}{\partial R} \frac{1}{\left(1+R^{2}\right)} e^{-\tilde{k}_{T}^{2} / 4\left(1+R^{2}\right)^{1 / 2}},
$$

where $a_{m, l}$ are constants, $l_{i}, i=0,1$ are turbulent length scales, the frequency-dependent transverse length scale, $\bar{l}_{T}$, is modeled as

$$
\bar{l}_{T}=\frac{l_{2,3} \sqrt{2}}{\left[1+\tilde{\omega}^{2}\left(1+b \tilde{\omega}^{3}\right) /(1+b)\right]^{1 / 4}}
$$


where $b$ is a constant, the normalized frequency $\tilde{\omega} \equiv \omega l_{0} / U_{c}$, with $\omega$ being the radian frequency, $U_{c}$ the convection velocity of the turbulence, $\tilde{k}_{T}^{2} \equiv\left(k_{2}^{2}+k_{3}^{2}\right) \bar{l}_{T}^{2}\left(1+\tilde{\omega}^{2}\right)^{1 / 2}$ is a normalized transverse wavenumber and $R^{2} \equiv \tilde{\omega}^{2}+\tilde{k}_{1}^{2}$,with $\tilde{k}_{1} \equiv\left(k_{1}-\omega / U_{c}\right) l_{1}$.

The operators $D_{k_{1}}$ and $D_{\tilde{\omega}}$, are defined as

$$
D_{k_{1}} \equiv\left(\frac{l_{1}}{l_{0}} \frac{\partial}{\partial \tilde{\omega}}+\frac{\partial}{\partial \tilde{k}_{1}}\right)\left(\frac{l_{1}}{l_{0}} \tilde{\omega}+\tilde{k}_{1}\right) ; D_{\omega} \equiv \frac{\partial}{\partial \tilde{\omega}} \tilde{\omega} .
$$

In References 28 and 29 the source model described above was used to model the momentum-flux source terms of the generalized acoustic analogy formulation for noise predictions in cold jets. In these calculations, the enthalpy-flux source terms were neglected (i.e., $R_{\lambda j \kappa l}$ was replaced by $R_{i j k l}$ ). Afsar, Goldstein and Fagan (Ref. 31) analyzed the enthalpy-flux source terms of the generalized acoustic analogy with the aim of reducing the number of independent spectral components contributing to the acoustic spectrum and understanding the structure of the remaining terms. For the former, they used the symmetry properties of the generalized Reynolds stress auto covariance tensor, introduced two kinematic approximations (consistent with those made in References 28 and 30 for the momentum-flux source terms) and exploited the disparity of the turbulence correlation and mean flow length scales. Their analysis expressed the total acoustic spectrum in terms of contributions from momentum-flux auto covariance, enthalpy-flux/momentum-flux covariance and enthalpy-flux auto covariance source terms. The latter two are additional terms, beyond the momentum-flux terms, that generally need to be included for noise predictions in heated jets.

In this paper, predictions for cold jets are carried out neglecting all enthalpy-flux source terms, and the formulation in Reference 31 is used to include the enthalpy-flux auto covariance source terms, which are expected to be the dominant ones in the moderate Mach number, moderately heated jets considered here, in a case where the core stream is heated relative to the ambient. We use the same functional form described above (but with different source coefficients) to model the enthalpy-flux auto covariance source terms. An approximation for the amplitude scaling of these terms is obtained by assuming a quasi-normal form and neglecting enthalpy-momentum correlations as

$$
R_{4 i, 4 i}(\boldsymbol{y}, \boldsymbol{0 , 0}) \approx(\gamma-1)^{2} \overline{\rho^{2}} \overline{\left(h_{t}^{\prime}\right)^{2}\left(v_{i}^{\prime}\right)^{2}}
$$

Since the Reynolds-averaged Navier-Stokes solver used in this work does not provide for evaluation of the enthalpy (or temperature) variances, an approximation for the total enthalpy variance, $\overline{\left(h_{t}^{\prime}\right)^{2}}$, was obtained using the Empirical Temperature Variance (ETV) model (Ref. 32). The latter was developed for single-stream round jets and its use here is an extrapolation of the model to multi-stream jets.

\section{Prediction Results}

\section{A. Flow}

In this subsection, results from the Reynolds-averaged Navier-Stokes (RANS) solutions used as input to the noise prediction method are presented and compared with PIV data. Examples of the quality of the representation of the azimuthal variation of the mean-flow-dependent coefficients of the Green's function Equation (11) by a finite number of azimuthal modes in an offset third stream case are shown.

The RANS solutions were obtained using the WIND US code (Ref. 33) with the Mentor Shear Stress Transport (SST) model. 


\section{Axisymmetric}

Figures 16 and 17 show contours of the acoustic Mach number and turbulent kinetic energy obtained from the RANS solutions for the axisymmetric case with $\mathrm{A}_{\mathrm{b}} / \mathrm{Ac}=1.0, \mathrm{~A}_{t} / \mathrm{A}_{\mathrm{c}}=1.0, \mathrm{NPR}_{\mathrm{c}}=1.8, \mathrm{NPR}_{\mathrm{b}}=1.6$, with all streams cold, with and without a third stream, respectively. Results from the RANS solutions suggest that the effect of the third stream is to move the end of the primary core (marked by vertical bars) downstream relative to the case without a third stream. The levels of peak turbulent kinetic energy in the two cases are about the same, $\left(k / U_{J}^{2}\right)_{\text {peak }}=0.026$, with the peak occurring very slightly further downstream in the case with the third stream.
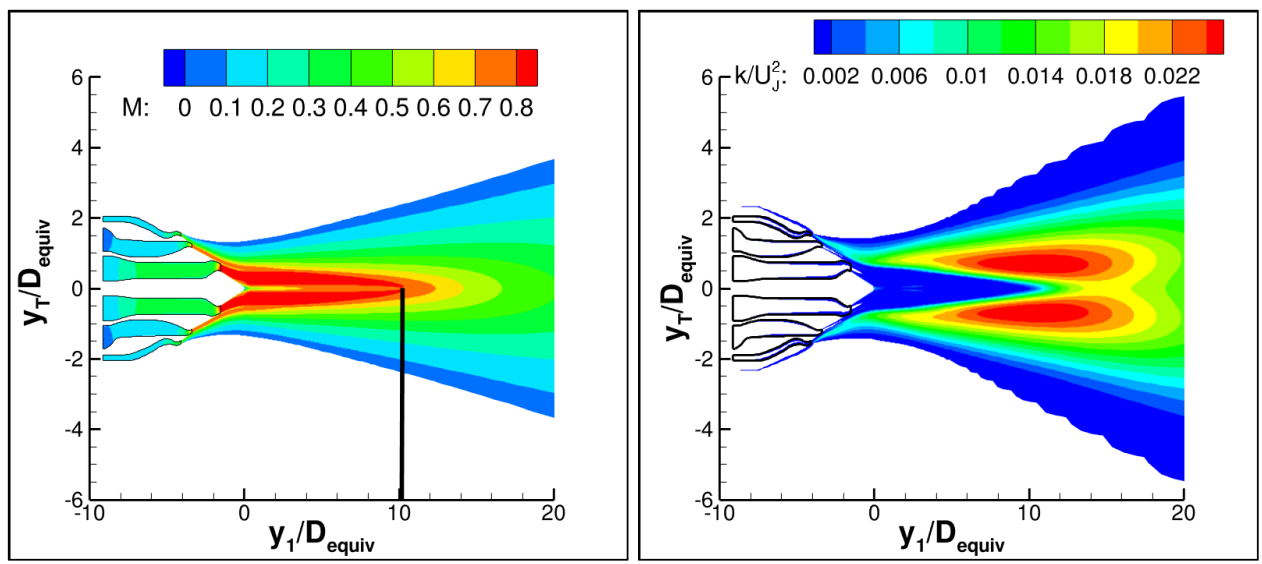

Figure 16.-Acoustic Mach number (left) and turbulent kinetic energy (right) contours; $N P R_{t}=1.2$.
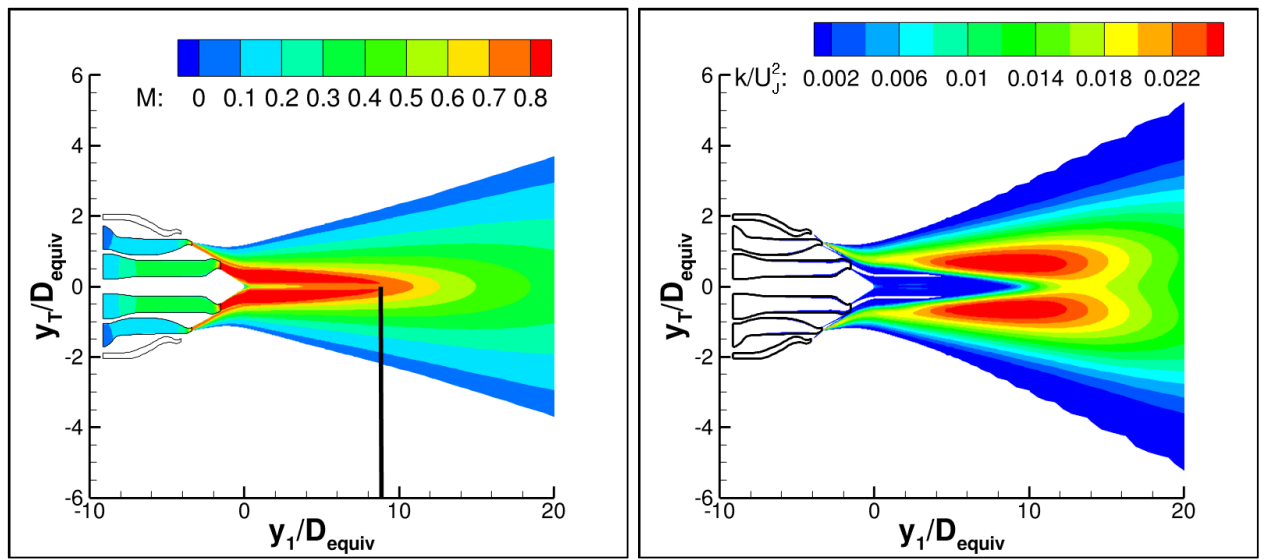

Figure 17.-Acoustic Mach number (left) and turbulent kinetic energy (right) contours; no third stream. 
Figures 18 and 19 show comparisons of results from the RANS solutions with PIV data for the case with the third stream. In Figure 18(a), contours of the mean streamwise velocity, normalized by the ideal core jet exit velocity, are shown, with the RANS solution in the upper part and the PIV data in the lower part. Figure 18(b) shows the corresponding turbulent kinetic energy. Figure 18(a) shows that the RANS predicts a slightly shorter primary core length compared with the data and Figure 18(b) that significantly higher turbulence levels are predicted by the RANS. Figure 19 shows the streamwise variation in the normalized mean streamwise velocity on the centerline and at a location just off the centerline, and the normalized turbulent kinetic energy at a radial location near the maximum turbulence level, from the RANS and PIV. On the centerline, the RANS over-predicts the length of the viscous wake behind the nozzle plug, while just off the centerline the RANS can be seen to predict a slightly shorter core length. The comparison of normalized turbulent kinetic energy shows that the RANS over-predicts the turbulence levels near the end of the plug, but levels closer to the data are predicted near the end of the measurement region. RANS solutions are known to generally over-predict the turbulence levels in high-speed jet flows (Ref. 34). The differences here are somewhat greater than those seen in simpler geometries, possibly indicating additional challenges for RANS-based calculations in more these more complex nozzle configurations. We note that the turbulence levels obtained from the RANS solution for the case without a third stream (not shown) are in somewhat better agreement with the PIV data.

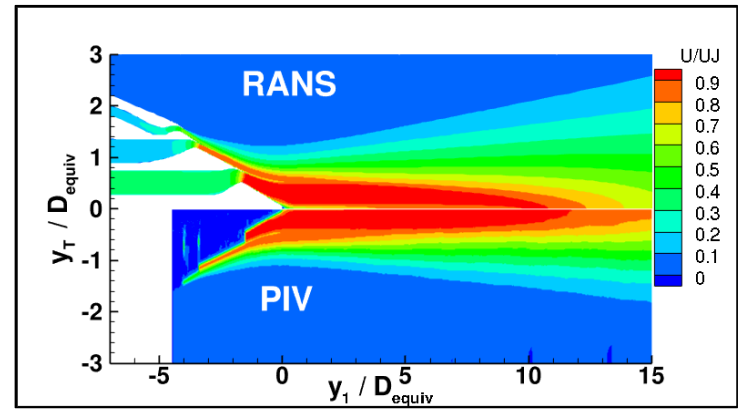

(a)

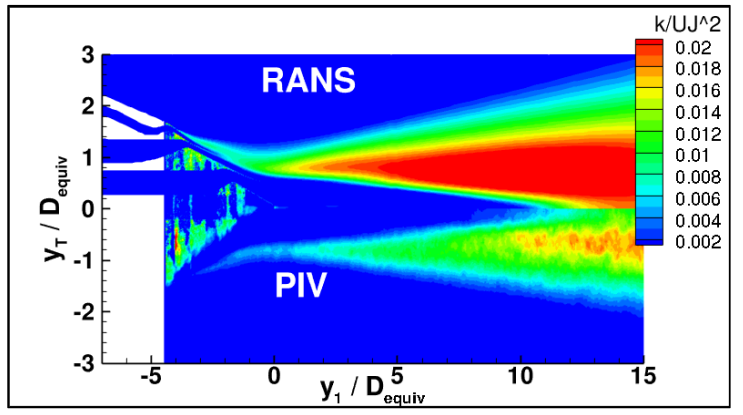

(b)

Figure 18.-Comparisons of RANS solution with PIV data for three-stream axisymmetric case.

(a) Normalized mean streamwise velocity. (b) Normalized turbulent kinetic energy.

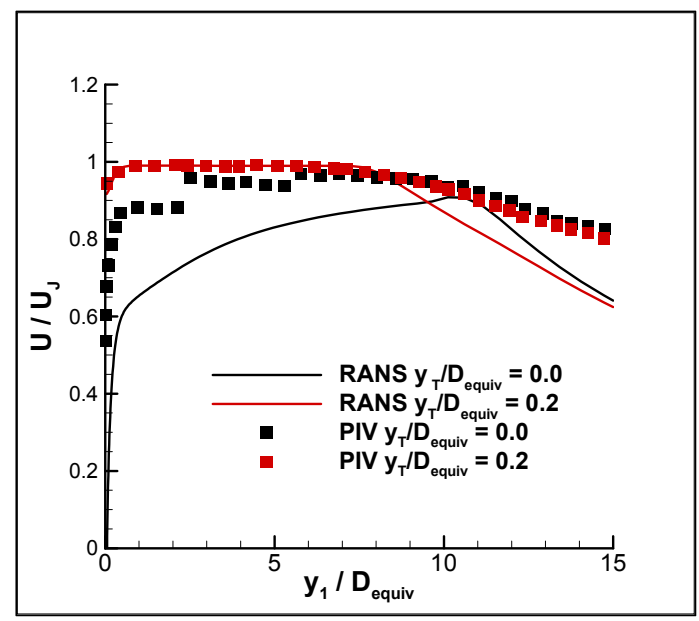

(a)

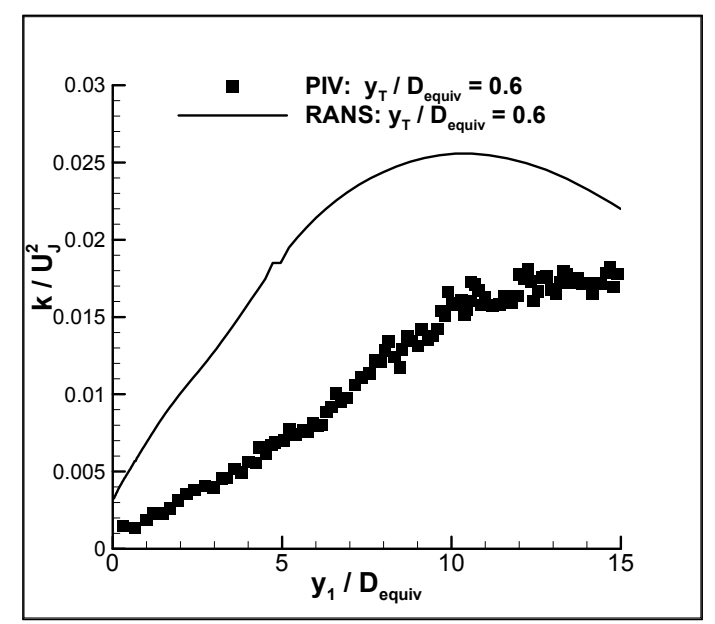

(b)

Figure 19.-Comparison of RANS solution with PIV data. (a) Normalized mean streamwise velocity. (b) Normalized turbulent kinetic energy. 


\section{Offset Third Stream}

Figure 20 shows contours of the mean acoustic Mach number and turbulent kinetic energy from the RANS solution in a number of axial slices through the jet, for the case: $A_{b} / A_{c}=1.0, A_{t} / A_{c}=1.0$, $\mathrm{NPR}_{\mathrm{c}}=1.8, \mathrm{NPR}_{\mathrm{b}}=1.6, \mathrm{NPR}_{\mathrm{t}}=1.2$, with all streams cold and the third stream offset. The third-stream offset results in a thick and a thin side to the jet, in terms of its mean velocity profile, and a significant shift of the turbulent kinetic energy to the thin side.

Figure 21 shows comparisons of the normalized mean streamwise velocity from the RANS solutions and PIV data for this cold offset case. The plots show contours of the normalized mean streamwise velocity in cross-flow planes at a number of streamwise locations downstream of the end of the nozzle plug. Experimental data is shown in the upper parts and RANS results in the lower parts of these plots. Close to the end of the nozzle plug there are significant differences between the shapes of the contours from the PIV and RANS. Further downstream the shapes become more similar, but the RANS solution seems to mix out to an axisymmetric mean flow closer to the end of the nozzle plug than the data indicates. Comparisons (not shown) of turbulent kinetic energy from the RANS solution with PIV data for this case show that the former predicts the significant shift of higher turbulence levels to the thin side of the jet as seen in the data (Fig. 20(b)), but the peak levels exhibit differences similar to those of the axisymmetric case in the last subsection.

Figure 22 shows comparisons of the normalized mean streamwise vorticity from the RANS solutions and PIV measurements. The presentation of these plots is the same as those in Figure 21, but different streamwise locations are shown. Very close to the end of the nozzle plug, a region of significant mean streamwise vorticity was found in the PIV data. The RANS solution also exhibits this streamwise vorticity, but at a slightly different location and the RANS result tends to dissipate the vorticity too quickly as the flow evolves downstream. The generation of significant levels of streamwise vorticity in the region near the end of the nozzle plug would result in enhanced mixing and could be partially responsible for the reduction of low- and mid-frequency noise observed in some of the three-stream nozzle configurations studied. The model used for noise predictions in this paper does not explicitly account for the presence of mean streamwise vorticity (Eq. (10)), but some of its effects, through its impact on the mean streamwise velocity and turbulence, may be manifest indirectly.

Figure 23 shows the azimuthal variation of the mean-flow-dependent coefficients of Equation (11), for $\vartheta=30^{\circ}\left(\theta=150^{\circ}\right)$, determined from the RANS solution and as represented by four azimuthal Fourier modes at two locations within the jet. There is some discrepancy between the Fourier representation of $R$ near $\varphi_{0}=0, \pi$, but for the most part, the coefficients are well represented by this relatively small number of modes, an important result for the viability of the noise prediction method for non-axisymmetric jets.

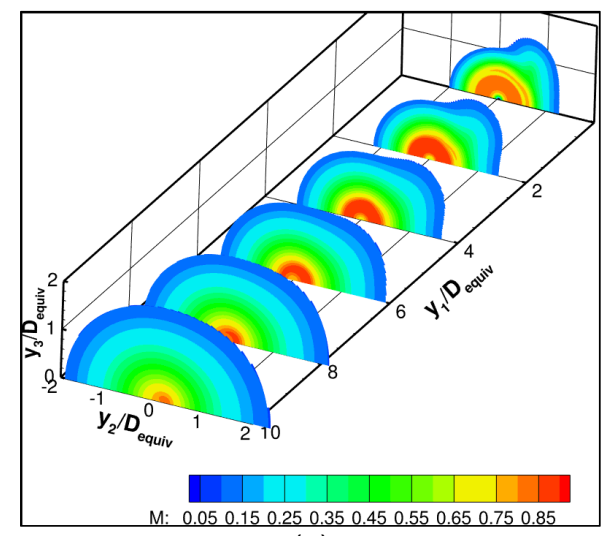

(a)

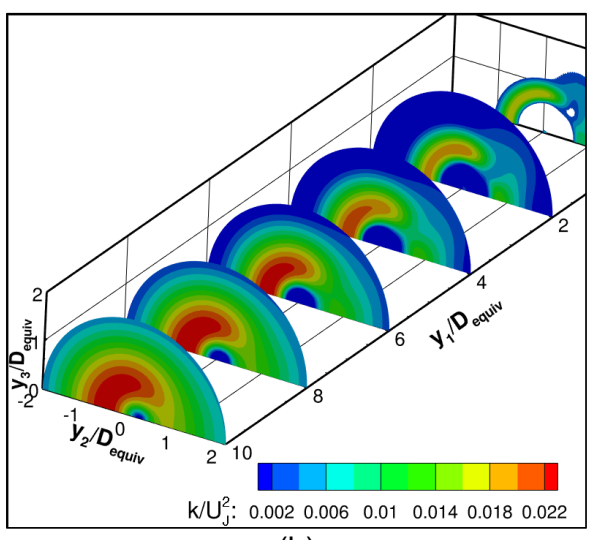

(b)

Figure 20.-Contours of (a) mean acoustic Mach number and (b) turbulent kinetic energy. 

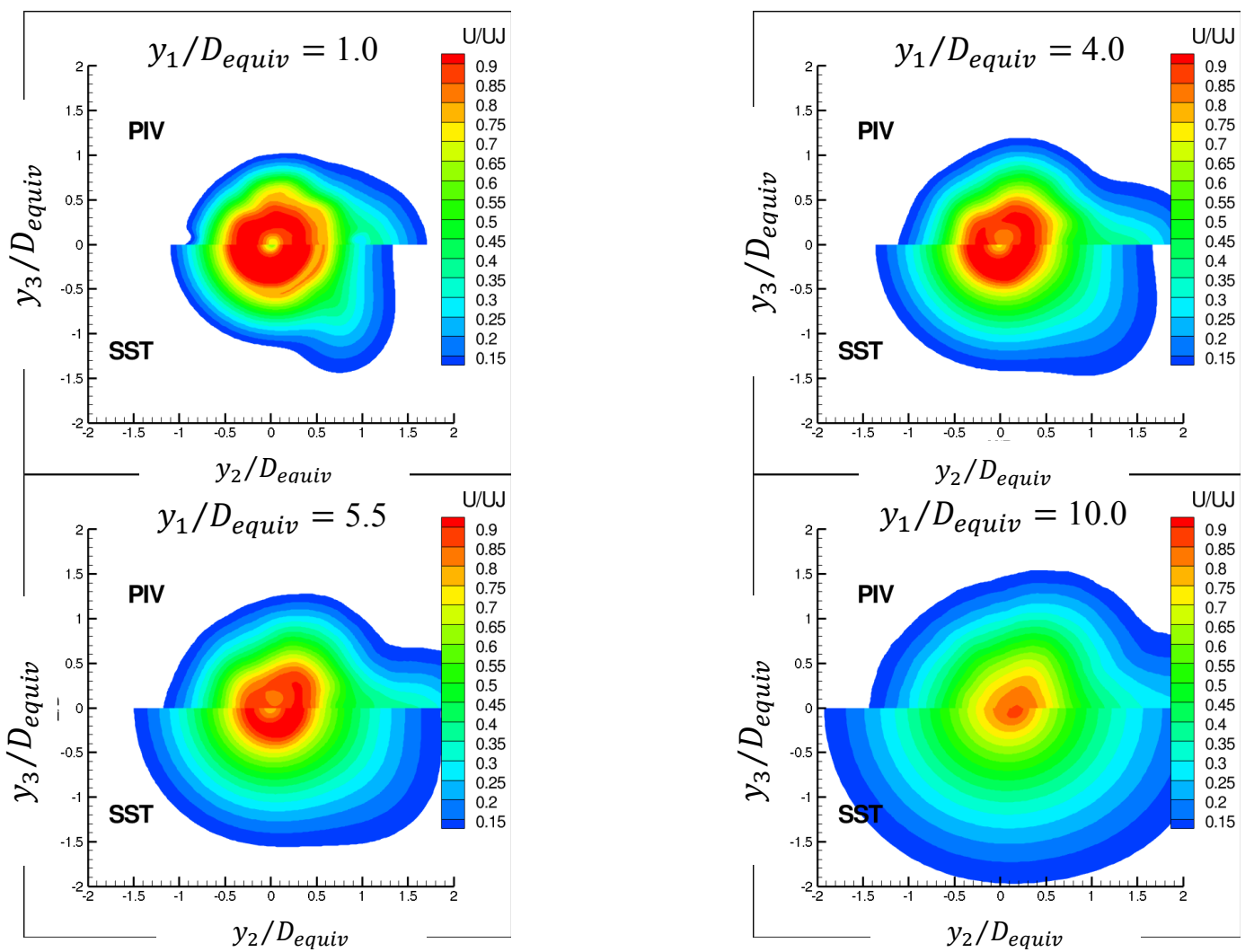

Figure 21.-Comparison of the normalized mean streamwise velocity in cross-flow planes at a number of axial locations. Cold, offset third stream case.
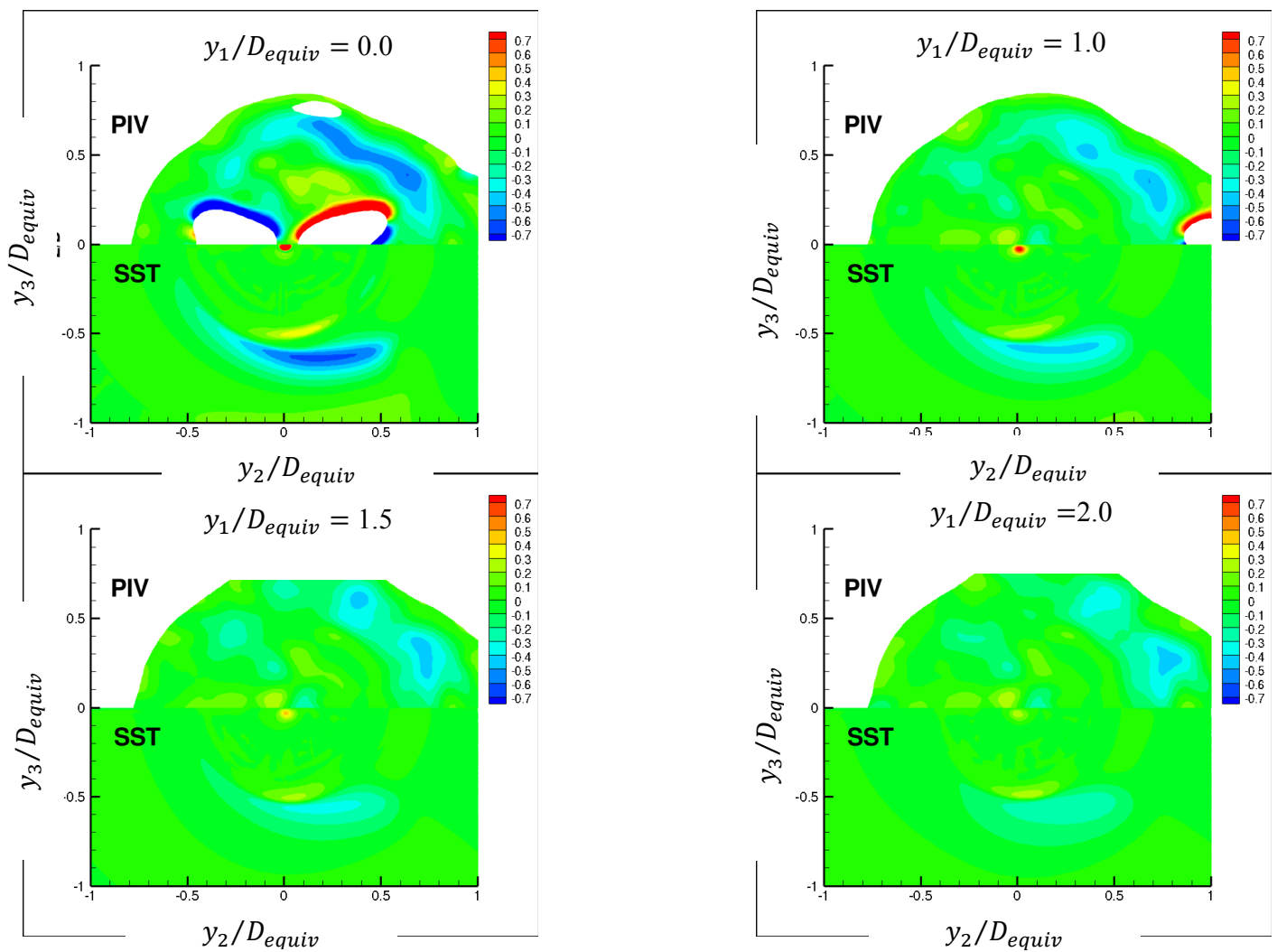

Figure 22.-Comparisons of normalized mean streamwise vorticity. 


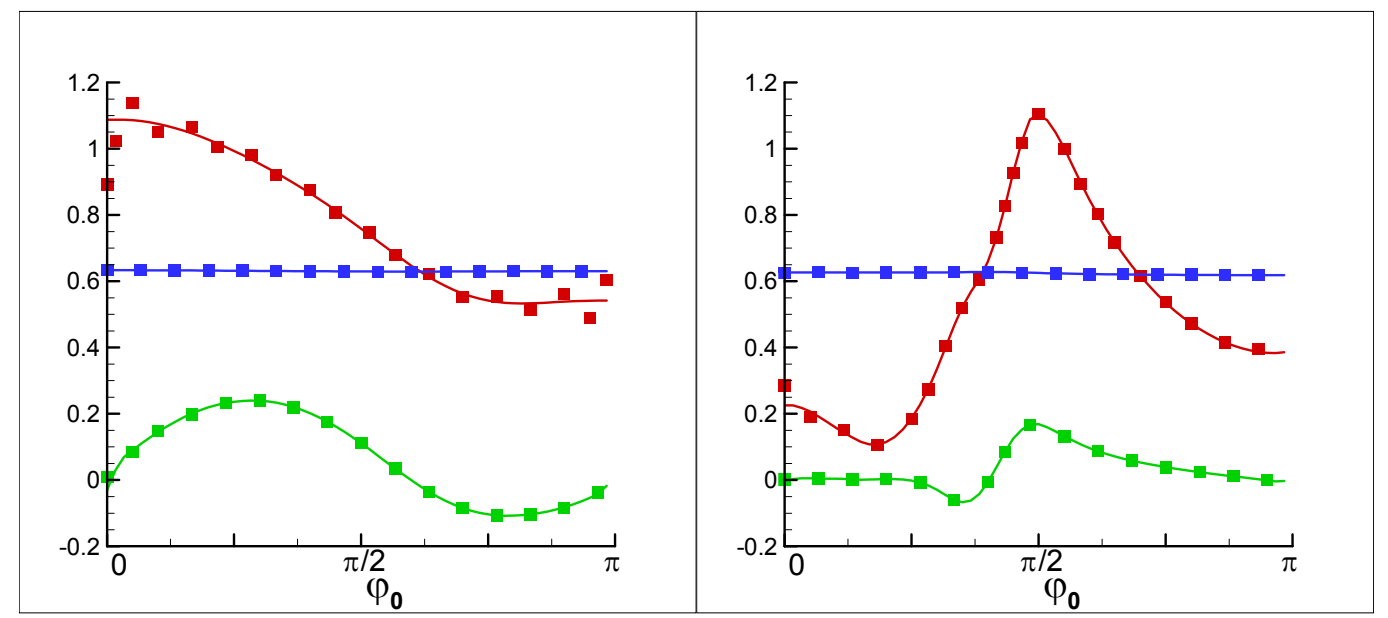

Figure 23.-Azimuthal variation of the mean-flow-dependent coefficients of Equation (11) and their representation by four Fourier modes. $R$, red; 7 , green; $\#$, blue. Curves from RANS solution, symbols from Fourier series. (a) $y_{1} / D_{\text {equiv }}=2.0, y_{T} / D_{\text {equiv }}=0.07$; (b) $y_{1} / D_{\text {equiv }}=4.0, y_{T} / D_{\text {equiv }}=0.4$.

\section{B. Noise Predictions}

\section{Axisymmetric}

In this subsection, prediction results are presented, based on the method in Reference 28, for two axisymmetric cases: $\mathrm{A}_{\mathrm{b}} / \mathrm{A}_{\mathrm{c}}=1.0, \mathrm{~A}_{t} / \mathrm{A}_{\mathrm{c}}=1.0, \mathrm{NPR}_{\mathrm{c}}=1.8, \mathrm{NPR}_{\mathrm{b}}=1.6$, with all streams cold, with $\left(\mathrm{NPR}_{\mathrm{t}}=1.2\right)$ and without $\left(\mathrm{NPR}_{\mathrm{t}}=1.0\right)$ a third stream. The coefficients in the source model are the same as those used in Reference 28.

Specifically, for the amplitudes of the various components of the Reynolds stress auto-covariance, $R_{i j k l}(\boldsymbol{y}, \mathbf{0}, 0)$, it is assumed that

$$
R_{i j k l}(\boldsymbol{y}, \mathbf{0}, 0) \approx C_{i j k l}(\bar{\rho} k)^{2}
$$

where the $C_{i j k l}$ are constants, $\bar{\rho}$ denotes the mean density and $k$ the turbulent kinetic energy determined from the Reynolds-averaged Navier-Stokes (RANS) computation. As in Reference 28, $C_{2222}=C_{3333}=0.159 C_{1111}, C_{2233}=0.0, C_{1122}=C_{1133}=0.047 C_{1111}$, and $C_{1212}=0.288 C_{1111}$. In order to set the absolute level of the turbulence (and therefore of the sound), the value for axial component of Equation (21) is set as $C_{1111}=2\left(\overline{v_{1}^{\prime 2}}\right)^{2} / k^{2}$ where, $v^{\prime}=\left\{v_{1}^{\prime}, v_{2}^{\prime}, v_{3}^{\prime}\right\}$, and $\overline{v_{1}^{\prime 2}}=0.8 k$. The length scales, $l_{1}, l_{2}=l_{3}=l_{T}$, are related to the RANS computations by setting $l_{1}=C_{1} k^{1 / 2} / \varepsilon$ and $l_{T}=C_{T} k^{1 / 2} / \varepsilon$. The specific values used for the constants in these length scales are shown in Table 2. The values of $a_{n, 0} / a_{0,0}$ are taken to be independent of the source location $y$ and the values used for the ratios of the coefficients in the truncated series representation Equation (17) are indicated in Table 3. In the model Equation (18) for the transverse frequency-dependent length scale, $b=0.1$ for the quadrupole-like terms and $b=0.5$ in the dipole-like term (Refs. 3 and 28). As in Reference 28, $U_{c}=0.68 U_{c l}$ where $U_{c l}$ is the jet centerline velocity, for the quadrupole-like source terms and $U_{c}=0.8 U_{c l}$ in the dipole-like term.

Figure 24 shows comparisons of the prediction results using this model with experimental data for the cold, axisymmetric case with $\mathrm{NPR}_{\mathrm{t}}=1.2$. Reasonably good agreement is obtained, with the predictions being generally within about $2 \mathrm{~dB}$ of the data. 
TABLE 2.-CONSTANTS USED TO DETERMINE THE LENGTH SCALES FOR THE INDICATED COMPONENTS OF THE TURBULENCE AUTO- COVARIANCE

\begin{tabular}{|c|l|l|l|}
\hline Component & $C_{0}$ & $C_{1}$ & $C_{T}$ \\
\hline 1111 & 0.7 & 1.2 & 0.4 \\
\hline $2222=3333$ & 0.7 & 0.8 & 0.89 \\
\hline $1122=1133$ & 0.7 & 1.1 & 1.0 \\
\hline 1212 & 1.05 & 1.0 & 1.1 \\
\hline
\end{tabular}

TABLE 3.-COEFFICIENTS IN THE TRUNCATED SERIES REPRESENTATION OF THE TURBULENCE SPECTRUM

\begin{tabular}{|c|c|c|c|}
\hline & $a_{1,0} / a_{0,0}$ & $a_{2,0} / a_{0,0}$ & $a_{3,0} / a_{0,0}$ \\
\hline 1111 & 0.073 & 0.070 & $-8.48 \times 10^{-4}$ \\
\hline $222=3333$ & 0.519 & 0.049 & -0.0097 \\
\hline $1122=1133$ & 0.103 & 0.079 & 0.0 \\
\hline 1212 & 0.559 & -0.006 & -0.015 \\
\hline
\end{tabular}

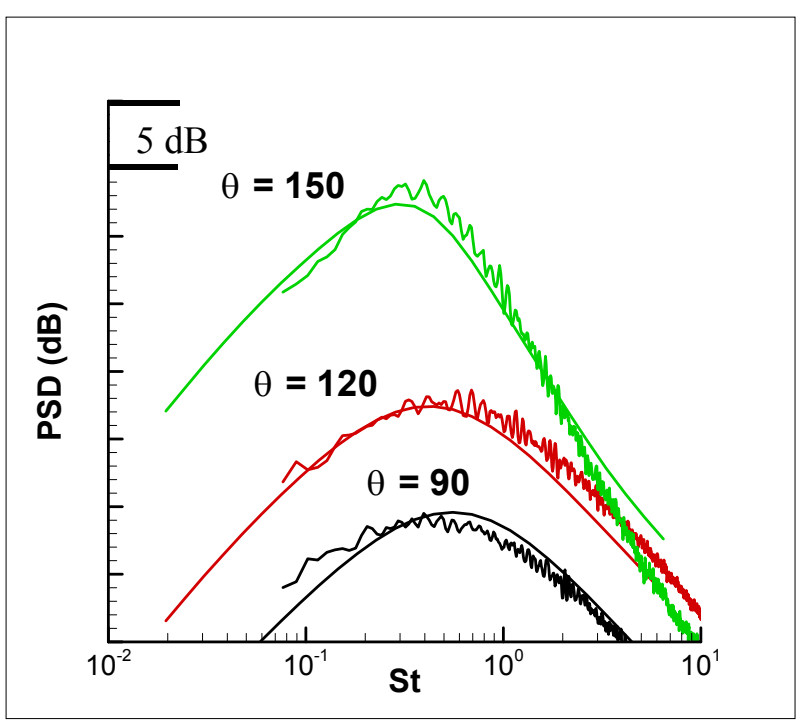

Figure 24.-Noise predictions for a cold, axisymmetric three-stream jet. Curves offset by $5 \mathrm{~dB}$ for clarity.

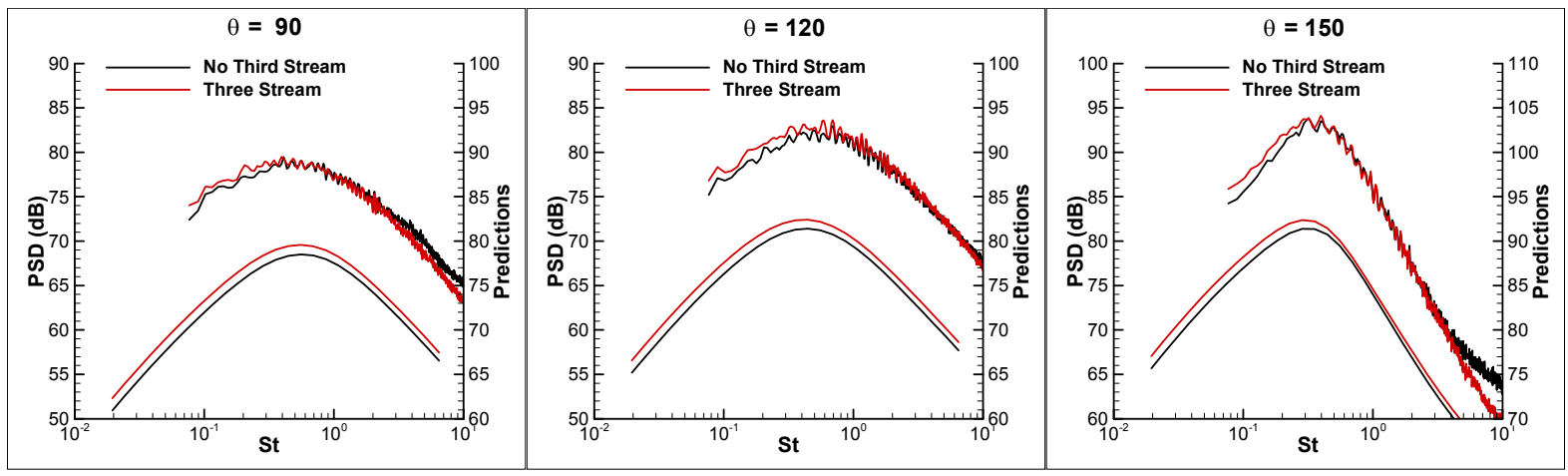

Figure 25.-Effect of third stream on axisymmetric cold case.

Figure 25 shows the effect of the third stream on the noise for the cold, axisymmetric case.

The experimental data (shown offset by $10 \mathrm{~dB}$ relative to the predictions) shows that the introduction of the third stream at $\mathrm{NPR}_{\mathrm{t}}=1.2$. results in a relatively small (about $1 \mathrm{~dB}$ or so) increase in noise at lowfrequencies at all polar angles shown, and a slight noise reduction at very high frequencies at $90^{\circ}$. The calculations predict that the introduction of the third stream increases the noise levels by a little more than $1 \mathrm{~dB}$ across nearly all frequencies at $90^{\circ}$, with less effect at high-frequencies in the downstream polar angles. 


\section{Offset Third Stream}

In this subsection, comparisons of prediction results are presented, using the approach in Reference 30 to obtain the Green's function, with experimental data for the case: $A_{b} / A_{c}=1.0, A_{t} / A_{c}=1.0$, $\mathrm{NPR}_{\mathrm{c}}=1.8, \mathrm{NPR}_{\mathrm{b}}=1.6, \mathrm{NPR}_{\mathrm{t}}=1.2$, with all streams cold and the third stream offset using an offset duct. The specific values used for the coefficients of the RANS-based length scales and of the ratios of the coefficients in the truncated series representation Equation (17) are the same as those used for the non-circular cases in Reference 29. The former are in listed in Table 4 and the latter are the same as in the axisymmetric calculations (Table 3 ). In the offset jet predictions, the convection velocity, $U_{c}$, is taken to be equal to the local mean velocity at the point of maximum turbulent kinetic energy.

Figure 26 shows the results of the comparisons for the cold offset case. The peak noise level at $90^{\circ}$, and its variation with polar angle in the downstream direction is relatively well predicted, as is the shape of the $90^{\circ}$ spectrum. At $150^{\circ}$, the predicted results peak at a lower frequency than the acoustic data, and do not exhibit the same degree of azimuthal variation between the thick and thin sides of the jet. It is possible that the rapid mixing of the flow in the RANS solution is partially responsible for the relative lack of azimuthal directivity in the noise predictions.

TABLE 4.-CONSTANTS USED TO DETERMINE THE LENGTH SCALES FOR THE INDICATED COMPONENTS OF THE TURBULENCE AUTO-COVARIANCE

\begin{tabular}{|c|c|c|c|}
\hline Component & $C_{0}$ & $C_{1}$ & $C_{T}$ \\
\hline 1111 & 0.7 & 0.95 & 0.32 \\
\hline $2222=3333$ & 0.7 & 0.63 & 0.71 \\
\hline $1122=1133$ & 0.7 & 0.87 & 0.79 \\
\hline 1212 & 1.05 & 0.79 & 0.89 \\
\hline
\end{tabular}

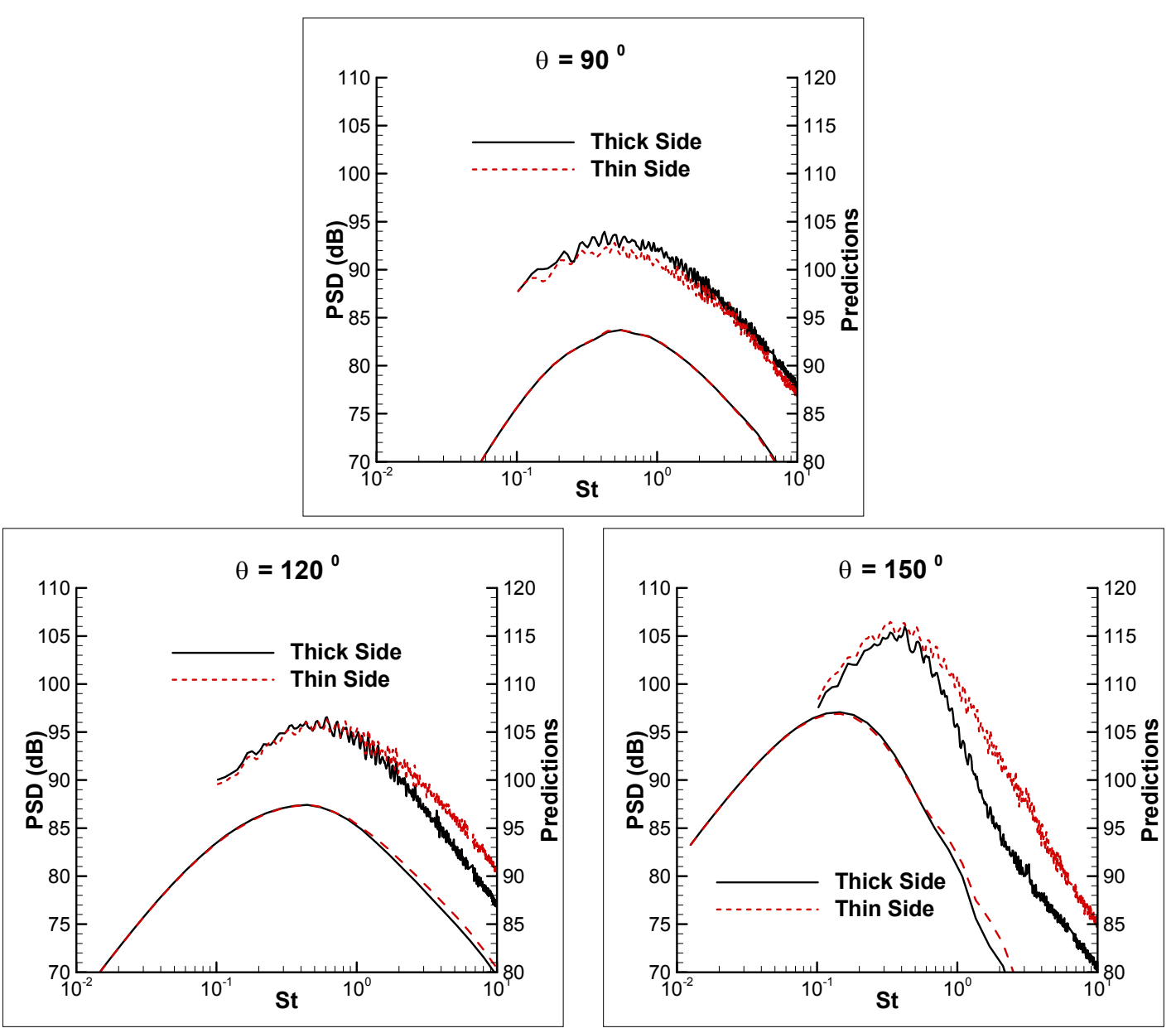

Figure 26.-Comparisons of predictions with data for cold offset case. 


\section{Hot Jet Predictions}

In this subsection comparisons of prediction results with experimental data are presented for the case: $\mathrm{A}_{\mathrm{b}} / \mathrm{A}_{\mathrm{c}}=1.0, \mathrm{~A}_{\mathrm{t}} / \mathrm{A}_{\mathrm{c}}=1.0, \mathrm{NPR}_{\mathrm{c}}=1.8, \mathrm{NPR}_{\mathrm{b}}=1.8, \mathrm{NPR}_{\mathrm{t}}=1.2, \mathrm{NTR}_{\mathrm{c}}=3.0, \mathrm{NTR}_{\mathrm{b}}=\mathrm{NTR}_{\mathrm{t}}=1.25$, with the third stream offset. For these calculations, the coefficients in the momentum-flux source terms were the same as those used in the cold offset predictions of the previous subsection. The coefficients in the enthalpy-flux source terms $(41,41$ and 42,42$)$ were taken to be the same as those of the corresponding momentum-flux terms $\left(11,11\right.$ and 22,22), except for the coefficients of the transverse length scales, $C_{T}$. The latter were set to: $C_{T}=1.5$ for the 41,41 component and $C_{T}=0.8$ for the 42,42 component. It was found necessary to increase the values of these coefficients above those used in the corresponding momentum-flux terms to match the rapid increase of the peak noise levels with increasing polar angle in the heated case. The scaling of the amplitude of the enthalpy-flux source terms was set using an approximation based on the Empirical Temperature Variance Model of (Ref. 32).

Figure 27 shows comparisons of the predictions with data for the heated case. Included on these plots are results obtained using only contributions from the momentum-flux source terms. These results are significantly below the data at all polar angles, suggesting the need for the additional enthalpy-flux source terms in this case. The results including the enthalpy-flux source terms are much closer to the data, and match the rapid increase of the peak noise levels with increasing polar angle in the heated case reasonably well. As mentioned above, the coefficients of the transverse length scales in the enthalpy-flux source terms were increased, making these terms more directional, to obtain these results.

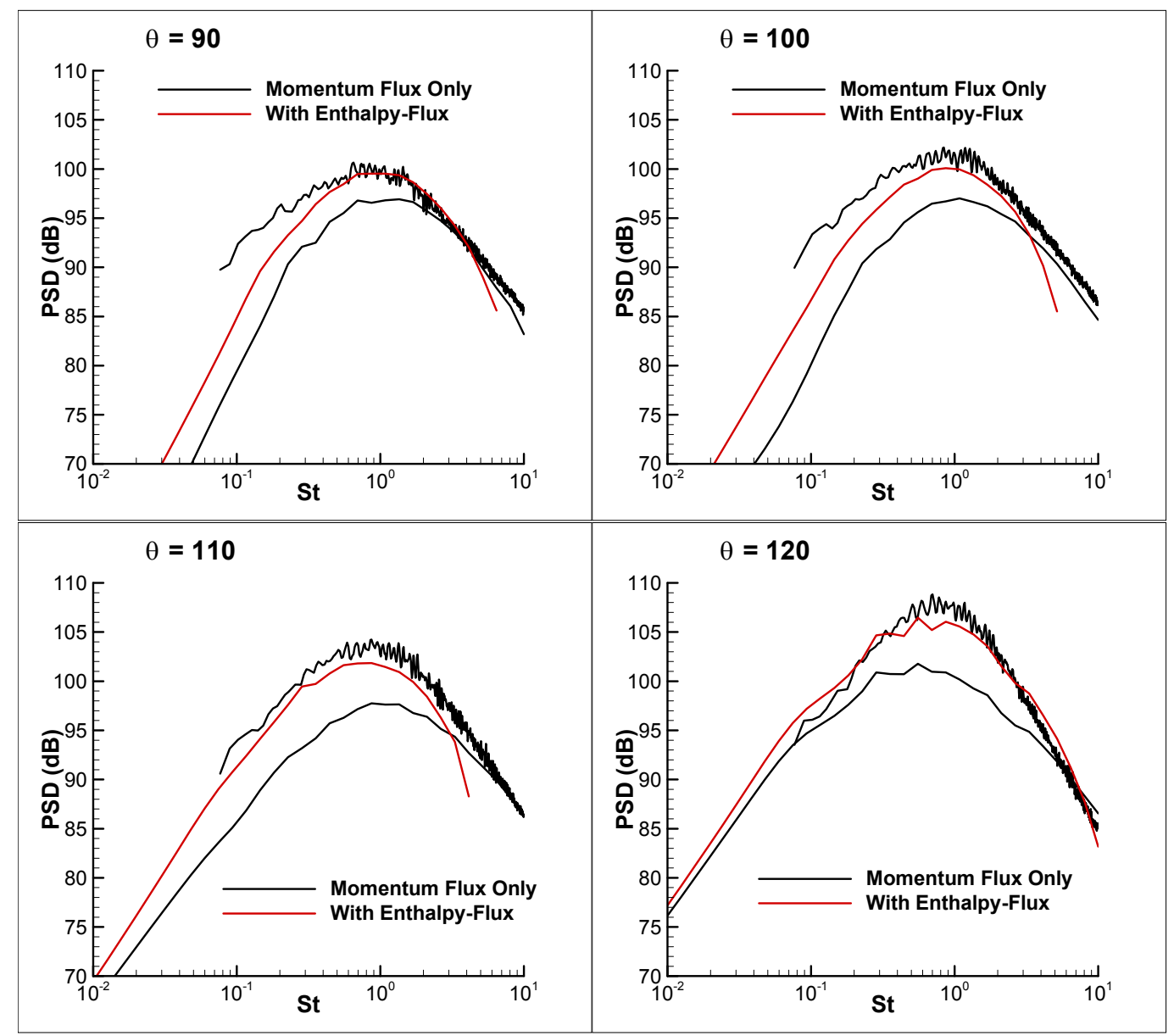

Figure 27.-Comparisons of noise predictions with data, hot offset case. 


\section{Conclusions and Discussion}

The introduction of an axisymmetric tertiary stream to a dual-stream nozzle system reduces acoustic radiation in the peak-jet-noise direction. The largest noise reductions (up to $3 \mathrm{~dB}$ ) are achieved for a nozzle system with a small bypass-to-core area ratio $\left(\mathrm{A}_{\mathrm{b}} / \mathrm{A}_{\mathrm{c}}=1\right)$. For small and broadside angles to the jet, the introduction of the third stream has no impact on low- and mid-frequency radiation for a large bypass-to-core area ratio $\left(A_{b} / A_{c}=2.5\right)$ or for a small tertiary-to-core area ratio $\left(A_{t} / A_{c}=0.6\right)$ and increased low-frequency radiation for a nozzle system with $A_{b} / A_{c}=1.0$ and $A_{t} / A_{c}=1.0$. An inverted third-stream velocity ratio, where the velocity of the third stream is larger than that of the bypass stream, results in elevated high-frequency radiation for all nozzle area-ratios and observation angles. For the same operating conditions and nozzle configuration, greater noise reduction is achieved for static simulated forward-flight conditions than for $\mathrm{M}_{\mathrm{fj}}=0.3$.

The introduction of asymmetry to the tertiary stream through partial blockage of the tertiary nozzle exit using nozzle inserts provides no acoustic benefit. Introduction of asymmetry to the tertiary stream using an offset duct placed just upstream of the tertiary nozzle entrance results in noise reduction (relative to the simulated two-stream jet) in the peak jet-noise direction on the thick side of the jet. For small bypass-to-core area ratios $\left(\mathrm{A}_{\mathrm{b}} / \mathrm{A}_{\mathrm{c}}=1.0\right)$, the introduction of the third stream at NPR $>1.3$ results in increased acoustic radiation throughout the spectra at small and broadside polar angles on the thick side of the jet and at all polar angles on the thin side of the jet. The offset duct is more effective at noise reduction for supersonic core conditions than for subsonic core conditions with a maximum noise reduction of $8 \mathrm{~dB}$ in the peak-jet-noise direction. At supersonic core conditions, noise reduction in the peak-jet-noise direction increases with increasing core nozzle-pressure ratio and decreasing bypass-tocore area ratio.

A small subset of the experimental cases was chosen for use as test cases for a RANS-based noise prediction scheme. RANS solutions were obtained for these cases and results were compared with PIV data. The RANS solutions were generally able to predict the trends associated with the effects of the third stream on the flow, but quantitative differences were found. It is possible that, for these relatively complex nozzle systems, the use of more advanced turbulence models could result in better predictions of the flow. Within the RANS context, an algebraic Reynolds stress model has been shown to provide improved flow predictions, compared with a two-equation model, for a high-speed elliptical jet with relatively little additional cost (Ref. 35). An algebraic Reynolds stress model would also provide additional information about the flow, such as the degree of anisotropy of the turbulence, which could be used to inform source models for noise predictions. Alternatively, a Large Eddy Simulation (LES) of the flow field could be carried out. The latter, of course, involves significantly higher computational costs, but the resulting unsteady flow solutions could provide, in addition to improved single-point turbulence statistics, further features of the flow, such as two-point, time-delayed velocity and velocity-enthalpy correlations and associated convection velocities. The use of more advanced turbulence models and LES for flow and noise predictions in three-stream jets will be a topic for follow-on research.

Noise predictions were calculated for the selected test cases using an acoustic analogy-based formulation, with the RANS solutions as input. The prediction method combines numerical solutions for the Green's function of the residual equations of the acoustic analogy in the locally parallel mean flow approximation with a source model constructed partially in the time-space domain and partially in the frequency-wavenumber domain. Results for an axisymmetric three-stream configuration, with all streams unheated, were in reasonably good agreement with data, but tended to over-predict the effect of the third stream on the noise at high frequencies for polar angles near ninety degrees to the jet axis.

Results for an offset third stream, also with all streams unheated, tracked the roughly $12 \mathrm{~dB}$ increase in noise from polar angles between $90^{\circ}$ and the peak noise direction, but over-predicted the shift of this peak to lower frequencies. Also, although the model qualitatively predicts the experimentally observed lower noise for observer locations on the thick side of the jet relative to the thin side at polar angles near the peak noise direction, the amount of azimuthal directivity is under-predicted. Reasons for this may have to do with the relatively quick mixing and transition to a nearly axisymmetric mean flow in the 
RANS solutions, or inadequacies of the source model in representing the azimuthal variation of the turbulence. Work is currently under way on an acoustic analogy formulation, and accompanying source modelling, that treats the azimuthal coupling of propagation and source components in a more rigorous way.

Results for an offset third stream with the core stream heated relative to the ambient showed the importance of including enthalpy-flux source contributions in noise predictions for heated jets.

Predictions for this case using only the momentum-flux source terms of the generalized acoustic analogy were more than $5 \mathrm{~dB}$ below the data for polar angles in the downstream quadrant. Inclusion of contributions from the enthalpy-flux auto covariance source terms gave much improved agreement with the data. It was found that model coefficients for the enthalpy-flux auto covariance source terms needed to be chosen to make the contribution from these terms more directional than the corresponding momentum-flux terms in order to match the rapid rise in noise level with increasing polar angle for the heated case. Work is also under way on improving the modeling of the enthalpy-flux auto-covariance source terms and incorporating the momentum-flux/enthalpy-flux covariance (coupling) terms in heated jet predictions.

\section{References}

1. Gillian, R.E., Aircraft Noise Prediction Program User's Manual, NASA TM-84486, 1982.

2. Khavaran, A., Bridges, J. and Georgiadis, N., "Prediction of Turbulence-Generated Noise in Jets," NASA-TM 2002-211696.

3. Goldstein, M.E. and Leib, S.J., "The Aeroacoustics of Slowly Diverging Supersonic Jets," Journal of Fluid Mechanics, Vol. 600, pp. 291-337, 2008.

4. Papamoschou, D. and Debiasi, M., "Directional Suppression of Noise from a High-Speed Jet," AIAA Journal, Vol. 39, No. 3, 2001.

5. Zaman, K.B.M.Q., "Noise- and Flow-Field of Jets from an Eccentric Coannular Nozzle," AIAA Paper 2004-5, 2004.

6. Murakami, E. and Papamoschou, D., "Mean Flow Development in Dual-Stream Compressible Jets," AIAA Journal, Vol. 40, No. 6, 2002.

7. Papamoschou, D., "New Method for Jet Noise Reduction in Turbofan Engines," AIAA Journal, Vol. 42, No. 11, 200.

8. Papamoschou, D., "Parametric Study of Fan Flow Deflectors for Jet Noise Suppression," AIAA Paper 2005-2890, 2005.

9. Zaman, K.B.M.Q. and Papamoschou, D., "Effect of a Wedge on Coannular Jet Noise," AIAA Paper 2005-0007, 2006.

10. Papamoschou, D., and Shuoe, R. S., "Effect of Nozzle Geometry on Jet Noise using Fan Flow Deflectors," AIAA Paper 2006-2707, 2006.

11. Henderson, B., Norum, T. and Bridges, J., "An MDOE Assessment of Nozzle Vanes for High-Bypass Ratio Jet Noise Reductions," AIAA Paper 2006-2543, 2006.

12. Dippold, V., Foster, L. and Wiese, W., "Computational Analyses of Offset-Stream Nozzles for Noise Reduction," Journal of Propulsion and Power, Vol. 25, No. 1, 2009.

13. Xiong, J. Nielsen, P., Liu, F. and Papamoschou, D., "Computation of High-Speed Coaxial Jets with Fan Flow Deflection," AIAA Journal, Vol. 48, No. 10, 2010.

14. Lighthill, M.J., "On Sound Generated Aerodynamically: I General Theory," Proc. Roy. Soc. London A, Vol. 211, 1952.

15. Papamoschou, D. and Rostamimonjezi, S., " Modeling of Noise Reduction for Turbulent Jets with Induced Asymmetry," AIAA Paper 2012-2158, 2012.

16. Brown, C., Bridges, J. and Henderson, B., "Offset Stream Technology Test - Summary of Results," AIAA Paper 2007-3664, 2007.

17. Henderson, B., “Aeroacoustics of Three-Stream Jets," AIAA Paper 2012-2159, 2012.

18. Papamoschou D., Johnson, A.D. and Phong, V. "Aeroacoustics of Three-Stream High-Speed Jets from Coaxial and Asymmetric Nozzles,” AIAA Paper 2013-0007, 2013. 
19. Soeder, R. H., Wnuk, S. P., and Loew, R. “Aero-Acoustic Propulsion Laboratory Nozzle Acoustic Test Rig User Manual,” NASA/TM-2006-212939, 2006.

20. ANSI S1.26-1995 (R2004), "Method for the Calculation of the Absorption of Sound by the Atmosphere".

21. Amiet, R.K., "Correction of open jet wind tunnel measurements for shear layer refraction," AIAA-77-54, 1977.

22. Wernet, J.H. and Wernet, M.P., "Stabilized Alumina/Ethanol Colloidal Dispersion for Seeding High Temperature Air Flows," Proceedings of the ASME Symposium on Laser Anemometry: Advances and Applications, Lake Tahoe, NV, 1994.

23. Gui, L., Werely, S.T., "A Correlation-Based Continuous Window-Shift Technique to Reduce The Peak-Locking Effect in Digital PIV Image Evaluation,” Experiments In Fluids, Vol . 32, 2002, pp. 506-517.

24. Wernet, M.P., "Symmetric Phase Only Filtering: a New Paradigm for DPIV Data Processing," Measurement Science and Technology, Vol. 16, 2005, pp. 601-618.

25. Taylor, J.R., An Introduction to Error Analysis, University Science Books, Oxford University Press, Mill Valley, CA., 1982, pp. 142-144.

26. Henderson, B., Kinzie, K., Haskin, H. "The Effect of Nozzle Trailing Edge Thickness on Jet Noise," AIAA Paper 2004-2948, 2004.

27. Goldstein, M.E., “A Generalized Acoustic Analogy,” Journal of Fluid Mechanics, Vol. 488, pp. 315-333, 2003.

28. Leib, S.J. and Goldstein, M.E. "Hybrid Source Model for Predicting High-Speed Jet Noise," AIAA Journal, Vol. 49, No. 7, 2011.

29. Leib, S.J., "Noise Predictions for Rectangular Jets Using a Conformal Mapping Method," AIAA Journal, Vol. 51 No. 3, pp. 721-737, 2013.

30. Leib, S.J., "Modeling Sound Propagation Through Non-Axisymmetric Jets," NASA-CR 2014218107, 2014.

31. Afsar, M.Z., Goldstein, M.E. and Fagan, A., "Enthalpy-Flux/Momentum-Flux Coupling in the Acoustic Spectrum of Heated Jets," AIAA Journal, Vol. 49, No. 11, 2011.

32. Khavaran, A. and Bridges, J.," An Empirical Temperature Variance Source Model in Heated Jets," NASA/TM-2012-217743, 2012.

33. Bush, R.H., Power, G.D. and Towne, C.E., "WIND: The Production Flow Solver of the NPARC Alliance," AIAA Paper 98-0935, 1998.

34. Dippold,V., "Acoustic Reference Nozzle with Mach 0.97, Unheated Jet Flow," NPARC Alliance Validation Archive, NASA Glenn Research Center, http://www.grc.nasa.gov/WWW/wind/valid/arn/index.html.

35. Yoder, D.A., "Initial Evaluation of an Algebraic Reynolds Stress Model for Compressible Turbulent Shear Flows," AIAA Paper 2003-0548, 2003. 

